Portland State University

PDXScholar

Spring 6-6-2018

\title{
Role of Spouse/Partner in Fertility Preservation Decision Making by Young Women with Cancer
}

Aakrati Mathur

Portland State University

Follow this and additional works at: https://pdxscholar.library.pdx.edu/open_access_etds

Part of the Social Work Commons

Let us know how access to this document benefits you.

\section{Recommended Citation}

Mathur, Aakrati, "Role of Spouse/Partner in Fertility Preservation Decision Making by Young Women with Cancer" (2018). Dissertations and Theses. Paper 4373.

https://doi.org/10.15760/etd.6257

This Dissertation is brought to you for free and open access. It has been accepted for inclusion in Dissertations and Theses by an authorized administrator of PDXScholar. Please contact us if we can make this document more accessible: pdxscholar@pdx.edu. 


\section{Role of Spouse/Partner in Fertility Preservation Decision Making by Young Women with Cancer}

by

Aakrati Mathur

A dissertation submitted in partial fulfillment of the requirements for the degree of

\section{Doctor of Philosophy}

in

Social Work and Social Research

Dissertation Committee:

E. Roberto Orellana, Chair

Pauline Jivanjee

Terri L Woodard

David Morgan

Portland State University

2018 
(C) 2018 Aakrati Mathur 


\begin{abstract}
Partners play a critical role in making decisions about fertility preservation among young patients with cancer, yet little is known about these dyadic decisions when planning cancer treatment. Fertility preservation entails helping cancer patients preserve fertility after cancer treatment. This qualitative study investigated: 1) Heterosexual couples' responses to potential fertility loss; 2) their process in making fertility preservation decisions; 3) their ethical and legal concerns, and 4) recommendations for other couples undergoing similar treatment.
\end{abstract}

Semi-structured interviews were conducted with 12 heterosexual couples whose female partners were diagnosed with cancer and had received fertility preservation consultations within the past 5 years. Interviews were recorded, transcribed, and analyzed using grounded theory methods.

The results indicated that couples have varied reactions to infertility. In most, spouses let the patients take the lead in, and supported, their fertility preservation decisions. Spouses recommended support to patients.

Couples face challenges in making fertility preservation decisions. Input from, and support for, both partners is essential to ensure well-informed, high-quality fertility preservation decisions. 


\section{Acknowledgments}

I would like to thank all of the participants who took part in the study willingly and whole heartedly. This is a sensitive topic and it is never easy to share these stories. I am very thankful to all my committee members for their feedback and guidance. I would especially like to thank Dr. Terri Woodard for giving me this opportunity at the MD Anderson Research Center. I also would like to express my gratitude to my advisor, Dr. E. Roberto Orellana, for his guidance and lending a patient ear to my struggles. I appreciate Dr. Pauline Jivanjee truly for her feedback and challenging me to produce an improved work.

Many thanks and heartfelt gratitude to my husband, Saurabh, for encouraging me to pursue this endeavor and supporting me through the process. Despite his own busy schedule, there were times when he assumed the full responsibility for our children so I could focus on my work.

In particular, I thank my parents, who taught me to dream big and aim high in life. 


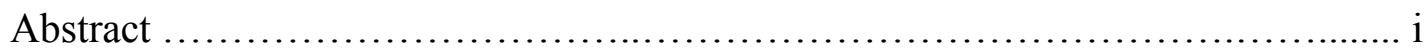

Acknowledgements...................................................

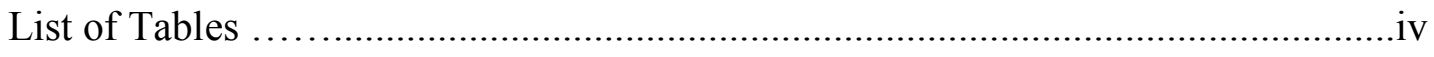

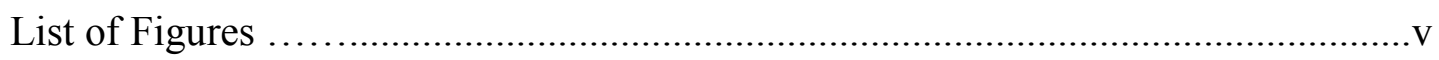

Chapter 1: Introduction..................................................

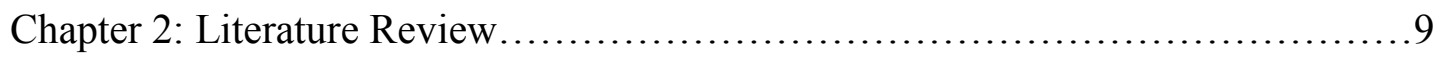

Chapter 3: Theoretical Framework.......................................... 34

Chapter 4: Research Questions and Methods.................................41

Chapter 5: Results.................................................... 51

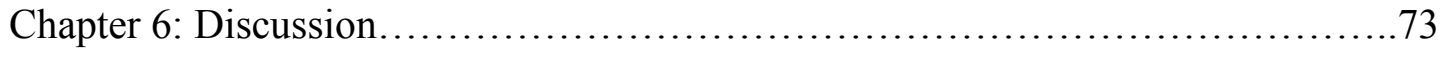

References....................................................... 96

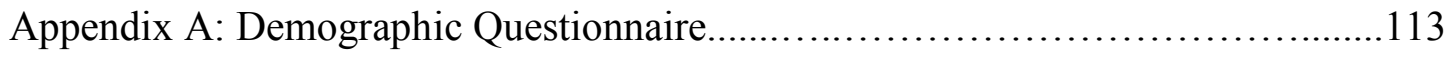

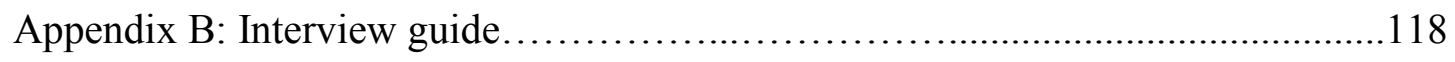

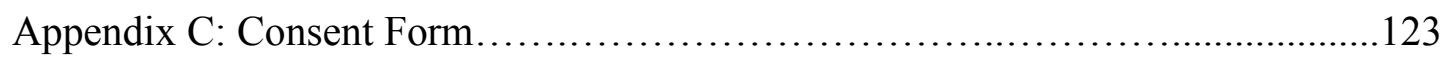

Appendix D: IRB Approval................................................ 131 


\section{List of Tables}

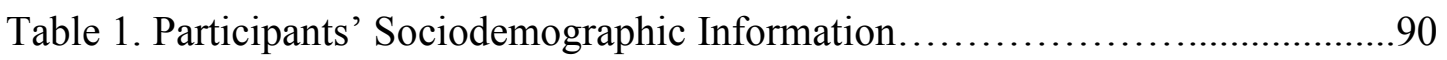




\section{List of Figures}

Figure 1. Ottawa Decision Support Framework..................................93

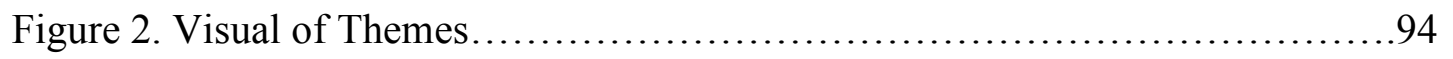

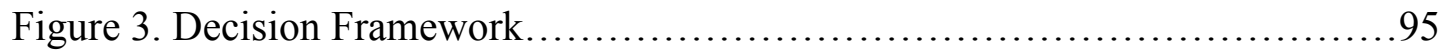




\section{Chapter 1: Introduction}

\section{Background of the problem}

Approximately 409.9 women per 100,000 people annually will develop cancer, and of these, $67.5 \%$ will survive (Noone et al., 2018). However, cancer treatment may lead to infertility among young women and a deterioration in their quality of life attributable to cancer-related stress (Woodard \& Hoffman, 2017; Schover, Rybicki, Martin, \& Bringelsen, 1999).

Infertility related to cancer treatment has received increasing attention in the past ten years. Women often delay pregnancy until their thirties and realize that cancer jeopardizes their reproductive life plans (Canada \& Schover, 2012).

Certain cancer treatments, including surgical removal of the reproductive organs, chemotherapy, or radiation, affect a woman's reproductive capacity. These effects may be temporary (treatment) or permanent (surgery) and can lead to compromised fertility immediately or in the future (Mayo Clinic Staff, 2014). Schover et al.'s (1999) study reported that $76 \%$ of younger cancer survivors without children not only expressed a desire to have children, but also were concerned about their potential reduction in fertility, possible treatment-related complications during pregnancy, and neonatal outcomes. The American Society of Clinical Oncology (ASCO) has recommended that oncologists discuss the possibility of infertility with reproductive-age cancer patients and offer referral for Fertility Preservation (FP) consultation and therapy. FP is an emerging field that provides treatment designed to protect the future reproductive viability of individuals with cancer or other serious illnesses. Although FP strategies vary according 
to the patient's age and sex, some allow patients to store gametes or reproductive tissues for future use (Jensen, Morbeck, \& Coddington, 2011). However, young women with cancer face many difficult decisions with respect to FP; they have different treatment paths and circumstances under which they may have to make this decision, and may be affected by the expected outcomes of the treatment they are undergoing. For example, some women treated for cervical cancer are unable to become pregnant because they have had a radical hysterectomy or a large dose of pelvic radiotherapy. Their decision to pursue FP may include considerations such as expensive treatment and help from surrogacy. Others in the early stages of the disease may be eligible for fertility-sparing surgical options, such as conization or trachelectomy. Trachelectomy is a surgical procedure for the early stages of cancer to protect fertility among women after the treatment. Irradiation of the uterus also can cause pregnancy complications, including miscarriage, premature birth, and low birth weights, which may dissuade women further from reproducing (Canada \& Schover, 2012). Other factors that may influence their decisions include occult damage to the heart or lung function after cancer treatment that can manifest in acute illness combined with the physiological stress of pregnancy. Some women opt out of pregnancy because they fear cancer recurrence or having a child with birth defects, although a large epidemiological study has shown no link between the effects of cancer treatment and giving birth to children predisposed to congenital abnormalities or even cancer itself, apart from those with familial malignant diseases (Hawkins, Draper, \& Smith, 1989).

\section{FP Decision Making}


Young women with cancer whose fertility may be at risk face difficult decisions regarding $\mathrm{FP}$, and very few studies have examined this decision-making process. Following diagnosis of early breast cancer, women need to make rapid decisions regarding fertility interventions before beginning treatment (Peate \& Meiser, 2012). The complexity of making FP decisions increases when ill-defined risk factors are present, such as fertility-treatment-induced increases in ovarian sex-steroid levels, which are contraindicated in women with breast cancer (Lee et al., 2006; Oktay et al., 2005; Partridge et al., 2007). Therefore, it is vital that clear and current information about fertility is provided in a timely manner (Peate \& Meiser, 2012)

There are several components in FP decision-making. Once the patients are informed that their fertility may be compromised, they face several dilemmas, including whether to opt for FP, whether it is worth paying for the treatment, whether they will be able to use their preserved eggs in the future, whether they are too young to preserve eggs, or whether they should opt for a sperm donor. These are but a few of the many questions that patients face when undergoing treatment that may cause infertility. The process of making decisions requires not only gathering information, but also seeking support from healthcare providers, family members, friends, and others. It is difficult for any single support system, whether it is family or a healthcare system, to provide all that is required in making such decisions. Patients also feel isolated while going through the process, as they find themselves at times in a unique position in which they know no one who has gone through a similar experience. They also face difficulties at various stages of decision-making, beginning in the first stage, when their physician provides them 
information about FP, to the final act of FP. Hence, there is a need to provide patients with support and help guide them as they make FP decisions.

For the purpose of this study, the female partner with cancer is referred to as the patient and her husband/life partner is referred to as the spouse/partner. A qualitative study which included individual interviews with patients and their spouses was conducted to explore FP decision making among young patients.

\section{Research objective}

This dissertation explored the following questions:

1) How does the knowledge of the potential risk of infertility affect couples?

2) What role do spouses/partners play in FP decision-making?

3) How are decisions negotiated?

4) What are the partners' ethical and legal concerns?

The primary objective of the study was to explore the role spouses play in FP decision-making.

This research explored factors and priorities that patients with cancer and their spouses/partners use to make decisions about FP. Findings from this research may help develop educational information and prepare such patient support tools as decision aids (DAs), develop interventions, such as counselling sessions, and organize support groups that will help patients make informed decisions about FP.

Studies have shown that educational materials, videos, pamphlets, and DAs help patients make decisions. For example, a meta-analysis of the literature was conducted to measure the effectiveness of cancer-related DAs. DAs improved knowledge about 
treatment options significantly by comparison to usual practices, and reduced anxiety and decisional conflict overall in decision-making (O'Brien, Whelan, Villasis-Keever, Gafni, Charles, \& Roberts, 2009). These aids do not advise people to choose one option over another, nor are they meant to replace consultation with practitioners. Instead, they prepare patients to make informed, value-based decisions with their practitioners. To develop such tools for use with FP, a formal study is needed to explore the spouse/patient FP decision-making process. These assessments are even required by some organizations, such as the International Patient Decision Aids Standards collaboration (IPDAS), as a part of a systematic process to develop such tools as DAs. This study will provide information that will help develop educational material, including DAs and interventions to improve support for affected women.

\section{Importance of the Study}

This dissertation focused on the role of spouses/partners in fertility decisionmaking on the part of young women with cancer. The study is relevant for women who are a part of a couple or have significant others. Women may make FP decisions individually, for example egg freezing; however, this study focused on couples who make decisions together. While multiple factors are involved, spouses/partners play a critical role in making fertility decision choices. For younger men, sperm freezing is considered a simple and highly successful FP strategy (Anderson et al., 2008) regardless of the recovery expectation of spermatogenesis (Peddie, Porter, Barbour, Culligan, MacDonald, \& King, 2012). Women who survive cancer may recover their fertility after completing treatment and retain reproductive function. However, fertility-related discussions become 
complicated when they reach the point of current relationship status, plans for children, and the range of FP options available. This may hinder providing information to the patients timely (Duffy et al., 2005; Quinn et al., 2007, 2008). Other studies have suggested that young early breast cancer patients have unmet needs for information related to fertility (Knobf, 2001; Partridge et al., 2004; Thewes et al., 2003, 2004, 2005 ). Peate et al. (2012) identified a gap in the literature about the spouse/partner's role in FP decision-making and stated:

Most participants reported that their partners were involved in the fertility treatment decision-making process, yet very little is known about how partners perceive their role despite fertility-related decisions being a decision for both parties. Understanding the mechanisms of fertilityrelated decision-making should incorporate this factor. (p. 106)

Most research in the area of FP has used data collected from women only. The reasons men were included in this study are: First, data from earlier studies have suggested that women seek support from family in decision-making, in which the spouse has a strong influence. Second, fertility and family-planning research has found that men and women have different attitudes about fertility that may have an influence on FP decision-making overall. Third, the literature also has suggested that men are more invested in having biological children than are women. Fourth, little literature is available on the spousal role in making FP decisions. Fifth, understanding spousal influence will help educate and provide support to couples as they make these decisions. 
Women's fertility choices affect men's lives as well, from becoming a father and the finances required to support children, to changes in their social status. Culturally, spouses have a strong influence on a women's choice to become a mother, and failure to involve them in decision-making may have serious implications. Despite educating women about FP methods, they may not opt for it if their spouses/partners oppose the decision. Hence, it is important to include the spouse/partner's perspective in FP decision-making. This dissertation will fill the gap in knowledge about the spouses/partner's role in FP decision-making on the part of young women with cancer.

This research explored this role by focusing on their preferences with respect to FP methods, whether they are aware of the various methods, and the way their future family goals compare with those of their spouses/partners. It is important to know whether both parties are knowledgeable about FP methods.

\section{Importance of the Study in the Field of Social Work}

Oncofertility is an interdisciplinary field (Atman, Ma, Duncan, \& Woodruff, 2018) and is described in detail in the literature review. This field requires cross discipline interactions inherently (Atman, et al., 2018), in which social work input is critical. This study is a part of the effort to contribute to this fast-growing field.

Responsiveness to individual needs is critical in FP decision-making (Logan, Perz, Usser, Peate, \& Anazoda, 2018). One of the goals of the study was to understand the patients' and their spouses' individual needs to make optimal decisions related to FP.

Studies have suggested that infertility is associated with long-term distress among women. Infertility after cancer treatment affects quality of life adversely and leads 
to emotional distress (Schover, 2005), and mere information about FP may not help in decision-making. Partridge et al. (2004) suggested that “...compared with participants who received usual care, those with access to the DA reported higher rates of satisfaction with the fertility information received $(>70 \%)$, which is above the $51 \%$ previously reported as having their concerns addressed adequately" (p. 4174). Using DA tools leaves women more satisfied with their choices and helps them deal with the pain of infertility (if any) after chemotherapy (Schwartz et al., 2010). Patients need individualized consultation to determine the best and most advance FP technology available in their unique circumstances and according to their informed choice ("What Are Social Workers' Roles in Oncofertility?”, 2015). Clinicians may not provide the psychosocial support that patients need to make FP decisions because of limited time, and thus, the social worker's role comes to the fore when providing this support. Many social workers also provide consultation for patients and serve as a patient navigator who offers support and guidance to their patients throughout the FP process as well as coordinates their care. An interdisciplinary team may help support the patients and may include oncologists, gynecologists, nurses, and social workers.

To develop counselling aids and training material for patient navigators, formal qualitative research needs to be conducted to understand and explore the decision-making process among patients and their spouses/partners. This dissertation will help Oncology Social Workers be proactive in helping patients who are experiencing infertility attributable to cancer treatment. 


\section{Chapter 2: Literature Review}

\section{Summary}

The literature review will cover the current scope of the problem, existing clinical practices, guidelines, and the need to develop tools to assist patients with FP decisions. This review will examine the extent of the problem and the fact that it is a growing burden on the healthcare system. It also will explore and explain the significance and societal burden of infertility associated with cancer treatment and the emerging medical field of "oncofertility." The review also will explain what a DA is. Although the development of a DA is beyond the scope of this dissertation, the data collected and analyzed will be useful in developing DAs and other training materials.

\section{Scope of the Problem}

According to the American Cancer Society (2018), an estimated 1,735,350 new cancer cases will be diagnosed in the US in 2018. The age-adjusted cancer death rate overall declined from 215 per 100,000 in 1991 to 159 per 100,000 in 2015 (American Cancer Society, 2018). These numbers reflect improvements in diagnosis and treatment techniques. At the same time, this success draws attention to the need to focus on improving survivors' quality of life. Healthcare providers' goal should not be mere survivorship, but also the ability to lead a fulfilling life after cancer treatment, which includes having children.

\section{Infertility and distress}

Certain types of surgeries and radiation increase the risk of infertility among young women, and may be temporary or permanent. The effect of treatment on fertility 
varies according to the dosage administered, the patient's age, and the type of cancer and treatment; however, in any case, it may have a negative effect on cancer survivors' emotional and physical health. Young adults with cancer have reported that infertility is a significant health issue that leads to poor psychosocial outcomes (Schwartz et al., 2010). Advancements in FP technology can improve the chances of having children posttreatment and reduce the emotional distress of patients who have undergone cancer treatment. According to the ASCO's guidelines on FP:

As part of education and informed consent before cancer therapy, health care providers (including medical oncologists, radiation oncologists, gynecologic oncologists, urologists, hematologists, pediatric oncologists, and surgeons) should address the possibility of infertility with patients treated during their reproductive years (or with parents or guardians of children) and be prepared to discuss FP options and/or to refer all potential patients to appropriate reproductive specialists. Although patients may be focused initially on their cancer diagnosis, the Update Panel encourages providers to advice patients regarding potential threats to fertility as early as possible in the treatment process so as to allow for the widest array of options for FP. The discussion should be documented. (Loren et al., 2013, p. 2500)

\section{Barriers to Infertility Discussion}

A meta-synthesis of 76 studies on barriers to, and facilitators of, FP care, concluded that intrinsic factors related to patients' current state of health, values, belief 
systems, and communication behaviors, as well as their families and providers, affect discussions related to the potential loss of fertility (Panagiotopoulou, Ghuman, Sandher, Herbert, \& Stewart, 2018). Earlier studies have reported that fewer than $50 \%$ of reproductive-age survivors recall discussing fertility risks with a healthcare provider, and fewer than 30\% received FP therapies (Gwede et al., 2012; Quinn et al., 2009). The FP decision-making process is complicated and is associated with many barriers, including a lack of discussion of the issue, the urgency of treatment, a cautionary approach to experimental procedures, and staff assumptions about patients' needs (Peddie, Porter, Barbour, Culligan, MacDonald, \& King, 2012).

A study was conducted in Japanese clinics to determine provider factors that contributed to physicians' behaviors with respect to FP (Shimizu et al., 2012). Female and younger oncologists $(<50$ years) had a significantly higher probability of referring patients to reproductive specialists, and physicians who had better knowledge scores and positive attitudes about FP also were more likely to discuss potential fertility issues with cancer patients. According to Gwede et al. (2012), oncologists (i.e., surgical, medical, and radiation oncologists) differ in their practice behaviors, specifically referral and discussion of FP. There was a significant difference in discussions of the effects of treatment on the future fertility for cancer patients of childbearing age depending on oncology subspecialty. This research suggested that $82 \%$ of radiation oncologists "always/often" discussed the effects of treatment on fertility, compared to $51 \%$ of surgical oncologists. There were no significant differences between oncology specialty and referrals to reproductive endocrinologists reported, with $24 \%$ to $31 \%$ of all 
oncologist types reporting that they "rarely/never" refer patients of childbearing age to an infertility specialist or reproductive endocrinologist (Gwede et al., 2011). In addition to the lack of referrals, the risks of recurrence, lack of collaboration with reproductive specialists, and time constraints in the clinic were identified as major barriers to discussing FP with breast cancer patients (Woodard et al., 2017). According to a study by Shimizu et al. (2012), female and younger physicians, as well as physicians who work in a multidisciplinary environment, had positive attitudes about FP for breast cancer patients. The authors recommended the development of comprehensive and interdisciplinary programs to help healthcare providers meet the expectations and fertility needs of breast cancer patients (Shimizu, Bando, Kato, Mizota, \& Yamamoto, 2012). In the last five to ten years, significant efforts have been made to provide information and support to patients who are undergoing cancer treatment and may be at risk of infertility.

\section{Decision-making challenges}

While efforts are made to provide information on the risk of infertility, merely providing information does not assure the proper use of FP services. There are barriers to such discussions, including late delivery of pertinent information, psychological stress, fear of delaying cancer treatment, and cost (Woodard et al., 2017). Studies have shown that receiving specialized counseling about reproductive loss and pursuing FP is associated with less regret and an improved quality of life on the part of survivors, yet few patients receive this potential benefit. Women of reproductive age should have expert counseling and should be given the opportunity to make active decisions about preserving fertility (Letourneau et al., 2012). Women feel more confident about their decisions when 
counseled, regardless of whether they choose fertility treatment (Woodard et al., 2017).

Patients' access to FP care and information may depend on, and vary by, clinic and provider.

\section{Couples' decision-making and the role of spouses}

There is a gap in knowledge and information about couples' FP decision-making, and patients need to be supported throughout this process. Hence, specialized counselling and tools like DAs may ensure timely introduction of FP options during the initial weeks of cancer treatment planning. This dissertation focused on understanding and exploring spouses and patients' roles in the decision-making process.

\section{Cancer-related infertility}

Many premenopausal women who undergo chemotherapy experience chemotherapy-induced amenorrhea (cessation of the menstrual period), premature menopause, or infertility. Research has indicated that treatment-related menopause is less common in women younger than age 35 and often is related to the type of chemotherapy used, the dosage of the drugs, and the patient's age. Most premenopausal women will stop menstruating at least temporarily during or following chemotherapy. While they may have symptoms of menopause, using the term "menopause" is avoided, as many regain ovarian function even several years later, and even may become pregnant during amenorrhea. Instead, many doctors today prefer to use the term "chemotherapy-induced amenorrhea," or CIA (Johns Hopkins University, 2014).

Infertility leads to emotional distress and personal suffering (Verhaak, Smeenk, Evers, Kremer, \& Kraaimaat, 2007). Patients with a history of gynecologic cancer who 
have lost their fertility as a result of cancer treatment experience depression, grief, distress, and sexual dysfunction (Carter, Rowland, Chi, Brown, Abu-Rustum, \& Castiel, 2005). They have persistent emotional difficulties accompanied by physical pain and distress, which has a negative effect on their quality of life (Carter, Rowland, Chi, Brown, Abu-Rustum, \& Castiel, 2005). It has been documented well that it is difficult to cope with the loss of fertility in itself, and that, coupled with cancer treatment, the issue is even more stressful for patients (Carter, Rowland, Chi, Brown, Abu-Rustum, \& Castiel, 2005). Hence, the field of "oncofertility" research emerged.

\section{Emergence and Brief History of the Field of Oncofertility}

After the 1971 National Cancer Act was signed and new funds were allocated to cancer research, there was significant improvement in the survival rate of cancer patients, which reached 3.5\% of the US population (Woodruff, 2007). As healthcare providers began to see improvements in the survival rate, they also observed the increasing problem of the long-term side effects of treatment, and FP among young cancer patients emerged as a solution to the reproductive future of cancer patients (Woodruff, 2007).

The term "oncofertility" was introduced in 2006 and was described as a new field that focuses on the reproductive health and future of cancer survivors who may face infertility as a result of chemotherapy, radiation, or surgery (Woodruff, 2007).

Oncofertility patients include those in pediatric, adolescent, and young-adult stages of life. Oncofertility encompasses: (1) the science needed to develop new FP options for patients prior to the onset of cancer treatment; (2) the clinical specialties to integrate FP, family building, and hormonal management throughout survivorship, and (3) the 
academic scholarship to advance oncofertility communication, social science, and education (Waimey et al., 2013). In 2007, a book published by Northwestern University Medical School explained the term "oncofertility." It described the emergence of an interdisciplinary science that brought together oncologists, fertility specialists, and social scientists to provide holistic treatment to help cancer patients live fulfilling lives after cancer treatment (Woodruff, 2007). Further, according to Waimey et al. (2013), in 2007, the National Institutes of Health (NIH) funded a five-year Roadmap Grant for Medical Research to form the Oncofertility Consortium - a comprehensive interdisciplinary research effort that addressed the complex biomedical condition of fertility impairment in cancer survivors. The Oncofertility Consortium was comprised of researchers based at four core centers-Northwestern University, the University of California at San Diego, the University of Pennsylvania, and Oregon Health \& Science University — and its National Physicians Cooperative, which included more than 50 allied healthcare centers across the United States that implement oncofertility science and scholarship into the clinical setting and provide FP treatments to cancer patients (Woodruff, 2010). The Consortium's objective was to gather professionals from different fields, including scientists, clinical specialists, and academicians, to examine and overcome current reproductive barriers for cancer patients (Waimey et al., 2013).

Diverse professionals from various fields have played different roles in the advancement of the field. Oncofertility scientists work to improve the basic understanding of gamete development and maturation and to apply this understanding to FP techniques. Clinical practices and treatment protocols have been discussed and 
established. After working in group sessions on female and male FP, the advancement in the field and future opportunities over the following few years were discussed and documented (Waimey, 2013), as were different cases and scenarios. In discussing the current state of female FP research, participants recognized that, for women, embryo banking is the most mature FP technology, but it is not optimal for all females, including prepubertal girls and women who need immediate treatment, women with hormonesensitive cancers, or those who lack an available and suitable sperm donor (Ata et al., 2010; Duncan et al., 2011). Although advances in the fast-freezing vitrification of oocytes have led to increased success rates in oocyte banking, this technique still requires hormonal stimulation of patients to retrieve the oocytes, which may not be feasible for girls and some women (Noyes, Boldt, \& Nagy, 2010). Apart from the options mentioned above, an alternative is ovarian tissue cryopreservation that may cater to the needs of women and girls who cannot opt either for embryo or oocyte banking (Donnez et al., 2010, 2011). FP options historically have been available more readily for males than for females because of the relatively straightforward technique of sperm cryopreservation for post-pubertal males established in the 1970s (Glaser, Wilkey, \& Greenberg, 2000). Hence, recent research in FP has focused on the need to provide equal and similar care to women, despite more clinical efforts needed to ensure male patients' use of FP (Waimey, 2013).

Because we know that cancer therapy improves a patient's survival but affects reproductive health, FP now is an option available to patients to overcome the problem of infertility resulting from cancer treatment. Of the estimated 1.5 million men and women 
who were diagnosed with cancer in 2010, approximately $10 \%$ were younger than 45 years. For these individuals, cancer treatment can be lifesaving, but can affect reproductive capacity permanently (Jensen, Morbeck, \& Coddington, 2011). However, fewer than $5 \%$ of adults with cancer choose to protect their future fertility by having samples of their gametes frozen before undergoing treatment (Editorial, Lancet, April 2014, p. 361). Thus, there is a gap between the need for, and use of, FP technology. To address the issue of infertility and the growing field of FP technology, several clinical guidelines for healthcare providers have been developed to facilitate FP discussions and referrals.

\section{Adolescent and Young Adult Oncology}

The field of oncofertility is consistent with another emerging field, that of adolescent and young adult oncology (AYAO), which focuses on advancing research and clinical care to improve outcomes for cancer patients who are diagnosed between the ages of 15 and 39 years. This population constitutes $10 \%$ of all cancer patients and survivors of those same ages (Sender, 2011). As these are the primary reproductive years, fertility is of significant concern to AYAO patients and their clinicians. The primary barrier to care for this age group is that fewer providers discuss fertility options with their patients (Clayman et al., 2011; Schover et al., 2002; Sheth et al., 2012). It is important to ensure that adolescent and young adult patients are informed of both the fertility and hormonal effects of cancer treatment and are made aware as well of their options to preserve reproductive function prior to such treatment. At a working group of providers' session, guidelines were set to make clear that oncofertility information be disseminated 
to oncology practitioners (Waimey, 2013). For example, a comprehensive brochure about AYAO patients, including information about fertility and hormonal health, could be created. The group agreed that such education should be communicated to a broad range of healthcare providers, not just oncologists. Engaging nurses, clinical psychologists, and other members of the oncology team would allow individual practices to determine which team member providers could discuss oncofertility issues with patients best and provide referrals to reproductive specialists (Waimey, 2012). It was suggested that oncofertility information could be disseminated to the greater AYAO community through partnerships with advocacy groups, such as Stupid Cancer, and professional organizations, such as the ASCO. As the AYAO working group discussed the need to engage the greater oncology community in oncofertility, a session of the National Physicians Cooperative addressed ways to communicate to and within the reproductive community (Waimey, 2013).

In 2018, the National Comprehensive Cancer Network (NCCN) published guidelines for Adolescent and Young Adults (AYA) Oncology that focuses on treatment and management of cancer in the AYA group (Coccia et al., 2018). These guidelines suggest aspects of care for this group additional to those of adult care that includes risks involved in care, patient screening, diagnosis, and survivorship.

\section{Oncofertility Science Education}

In addition to the guidelines on FP treatment and counseling, a second group of scholars met to discuss the oncofertility community's science education efforts, which simultaneously educates young people about oncofertility and promotes the study of science and medicine on the part of young students (Waimey, 2013). According to 
Waimey (2013) the group stated that these two missions ensure that more young people are aware of the reproductive effects of cancer treatment and enter the pipeline to become the next generation of scientists and clinicians. In the past five to ten years, members of the Oncofertility Consortium have accomplished this by developing the Oncofertility National Science Education Network (ONSEN) at the four locations across the country mentioned above that together educate more than 250 high school students. The working group discussed that future ONSEN efforts will include assessment as a major goal and, in particular, evaluation of outcomes in a manner appropriate to the objective of the educational program. Such metrics can be used to inform educators developing the next generation of oncofertility leaders better and inform similar science education programs. Further, a "teach the teachers" program has been launched that allows high school teachers to participate in oncofertility research in a laboratory setting and develop curricula to implement in their classrooms (www.nubio.northwestern.edu). As the working group discussed, the principle advantage of this program is the ability to teach oncofertility to a greater number of students. Further dialogue identified the need for sustainability and funding to expand both programs and support new sites. Finally, working group participants stressed the need to ensure that these educational programs are integrated in existing local university and school environments to achieve sustainability.

\section{Guidelines and Clinical Practice}

\section{Guidelines}


The ASCO (Loren et al., 2013) introduced the guidelines first in 2006 and revised recommendations for healthcare providers (including medical, radiation, pediatric, and gynecologic oncologists, urologists, hematologists, and surgeons) to discuss FP methods with patients of reproductive age as early as possible in cancer treatment. This discussion can take place between the provider and patient or the patient's parent/legal guardian. ASCO developed a set of key recommendations after a systematic literature review published from March 2006 through January 2013 using MEDLINE and the Cochrane Collaboration Library (Loren et al., 2013). These guidelines were updated in 2018 (Oktay et al., 2018).

The following recommendations were made for clinical practices:

Recommendation 1: People with cancer are interested in discussing FP. Healthcare providers caring for adult and pediatric patients with cancer (including medical, radiation, gynecologic and pediatric oncologists, urologists, hematologists, surgeons, and others) should address the possibility of infertility as early as possible before treatment starts. Recommendation 2: Healthcare providers should refer patients who express an interest in FP (and those who are ambivalent) to reproductive specialists.

Recommendation 3: To preserve the full range of options, FP approaches should be discussed as early as possible, before treatment starts. The discussion can ultimately reduce distress and improve quality of life. Another discussion and/or referral may be necessary when the patient 
returns for follow-up after completion of therapy and/or if pregnancy is being considered. The discussions should be documented in the medical record. (Oktay et al., 2018)

An article on the changing perspective about improving access to FP (Cedars, Letourneau, Lisko, \& Rosen, 2011) suggested that clinicians must become more aware of their patients' desire to be mothers and about their individual reproductive potential. The authors suggested a collaborative approach between oncology and fertility teams to help patients understand their risk of treatment-related infertility better, as well as how to take effective measures to mitigate it. There are other clinical guidelines available from such organizations as the National Comprehensive Cancer Network, the International Society for Fertility Preservation, and the American Society of Registered Nurses.

\section{Clinical options for FP}

Several FP options are available for patients (Mayo clinic staff, 2014):

- Embryo cryopreservation. In this procedure, women receive ovarian stimulation, and eggs are harvested from the ovaries, fertilized with sperm through in vitro fertilization (IVF), frozen, and stored. This method has the highest chance of success for women.

- Egg freezing (oocyte cryopreservation). Similar to embryo cryopreservation, the patient receives injections of a medication that stimulates the ovaries, after which the unfertilized eggs are harvested and frozen. This is now an accepted practice, and has shown improved results. 
This procedure is ideal for women who do not have a sperm donor, have ethical concerns, or desire reproductive autonomy.

- Ovarian transposition (oophoropexy). This procedure is recommended for patients who are having pelvic radiation. The ovaries are repositioned surgically just before therapy so that they are as far as possible from the field of radiation planned. However, with scatter radiation, the procedure does not always protect the ovaries. After treatment, the ovaries may need to be repositioned again or IVF may be necessary to achieve conception.

- Shielding. Shields placed carefully can reduce reproductive organs' exposure to scatter radiation in patients who are having radiation applied to an area distant from the pelvis.

- Ovarian Suppression. This is applied when drug therapy or surgery is used to prevent ovaries from producing the estrogen tumors require to grow.

- Ovarian tissue cryopreservation. This is a method to preserve immature eggs by freezing the outer layer of the ovary for future use. When the frozen cells are thawed and then transplanted back to the ovary or fallopian tube, they can restore the ovary's function, such that it begins to produce eggs and hormones.

- Clinical studies of FP methods have indicated that shielding treatment can preserve fertility in some, but not all patients. Cryopreservation of ovarian tissue appears to be a very promising method of providing the cancer patient with a realistic chance of preserving fertility (Maltaris et al., 2007). 


\section{Current Status of Clinical Practice}

After the 2006 ASCO clinical guidelines for FP in cancer patients were issued, a study was conducted to identify the frequency of fertility discussions and the factors that influence the rate of such discussions (Kumar, Merali, \& Pond, 2012). Results of the survey indicated that discussions about fertility risks in cancer treatment were inconsistent and did not occur regularly among young adults diagnosed recently. Only $34 \%$ of patients between the ages of 20 and 40 referred for cancer treatment had a documented discussion regarding the fertility risks associated with treatment and the options available for FP. However, discussions occurred more frequently with younger patients and among those undergoing radiation (Kumar, Merali, \& Pond, 2012). Hence, more initiatives, such as establishing specific protocols to facilitate FP discussions and developing tools to educate patients, may be needed to promote adherence to the guidelines. Another study addressed the comprehension of the fertility discussions that did occur (Balthazar, Deal, Fritz, Kondapalli, \& Kim, 2012). Higher comprehension scores were associated with a college education, higher income, a primary diagnosis of breast cancer, additional contact with the FP specialist following initial FP consultation (FPC), and the use of specific reference websites, such as www.fertilehope.org. Parity, marital status, and completion of FP treatment were not associated with knowledge scores. FP knowledge following comprehensive FP consultation remains limited. Modifications to the current single-visit FPC, such as a standard follow-up visit or additional educational tools, may be needed to improve patients' understanding of complex FP treatment options (Balthazar, Deal, Fritz, Kondapalli, \& Kim, 2012). 
A systematic review of 23 studies conducted in May 2016 concluded that despite the fact that clinical guidelines had been published for the last 10 years, oncofertility support is still not delivered to the standard of the guidelines and providers fail to provide the care recommended for eligible patients (Logan, Perz, Ussher, Peate, \& Anazodo, 2018).

\section{Patient/provider Communication Relationship}

Studies have shown that patient/provider communication has an effect on positive outcomes among patients (Arora, 2003). A diagnosis of cancer is a life-changing incident. Patients experience many emotions, including denial, anger, fear, distress, depression, sadness, and loneliness. From diagnosis to treatment and remission, patients must deal with significant uncertainty and face several decision points. Making decisions based on insufficient data and unknown outcomes can be extremely stressful. In addition, patients are dealing with the side effects of chemotherapy and/or radiation, and time is not always on their side. In some situations, providers have to begin treatment immediately, which can be overwhelming for patients. In addition to the cancer treatment, FP choices can complicate the situation further for the patient as well as the family members and spouse/partner. Patients often rely on their physicians to provide them with social/interpersonal, informational, and decisional support (Arora, 2003), and communication plays a central role in providing quality patient care. Bakker, Fitch, Gray, Reed, and Bennett (2000) examined interactions between women with breast cancer and their cancer care specialists from the patients' perspective. Their study was conducted while the women underwent chemotherapy. From their narratives, several patients 
identified professional and contextual factors that influenced their perceptions about the quality of their communication experience. This study described the reports of 40 women who shared their experiences with their healthcare providers during cancer treatment. The findings suggested that patients seek practical and emotional support during treatment.

\section{Patient Referral}

Studies have indicated that it is not only the quality of communication that is important to improve the patient's overall outcome, but also that early referrals to fertility specialists are beneficial. One study was conducted to determine whether early referral to reproductive specialists improves FP outcomes and reduces the delay in adjuvant treatment in young women with breast cancer (Lee et al., 2006). Patients who had oocyte retrieval within five weeks of surgery were able to complete a second cycle within nine weeks. FP referral before breast surgery enabled earlier initiation of cryopreservation cycles and chemotherapy and, when appropriate, multiple FP cycles. Women who can undergo multiple cycles are at an advantage for FP, because a larger number of oocytes or embryos can be cryopreserved. This study indicated that early referral for FP among breast cancer patients most likely would have better results than when conducted later or post chemotherapy (Lee et al., 2006). This shows that earlier FP referrals have certain clinical advantages, as eggs can be harvested in multiple rounds. Thus, early referral is an essential intervention in FP and must be a part of FP discussions. This article suggested that failures in patient/provider communication that lead to later referrals can compromise the patient's fertility permanently (Lee et al., 2006). 
FP communication also depends on the patient's ethnicity. A study that focused on provider/patient communication about FP among African American women with cancer suggested that only certain populations had the opportunity to discuss FP, and that there is a need to improve the number of these patients who are made aware of FP options. The study showed that there is a disparity among ethnicities in receiving fertility information (Vadaparampil, Christie, Quinn, Fleming, Stowe, \& Bower, 2012).

\section{Spouse/partner concerns with infertility and FP options}

The effect on couple's relationships of infertility attributable to cancer has received less attention from researchers. There is evidence that infertility among couples leads to feelings of loss of control, perceived loss of femininity or masculinity, and loss of attractiveness or self-esteem (Oncofertility Consortium, 2013). Infertility attributable to cancer treatment may produce the same feelings of loss, coupled with the stress of dealing with cancer. There are several decisions that couples need to make when they opt for FP:

1) Which FP method should they use?

2) Should the cancer treatment be delayed for FP treatment?

3) What legal issues are involved?

4) What are the ethical and religious norms of each partner that need to be addressed before proceeding with FP?

5) What should be done with preserved eggs in the case of death or divorce?

Cancer patients have identified their partners/spouses as the partner who is used most often and is most helpful in fertility discussions (Tschudin, Bunting, Abraham, 
Gallop-Evans, \& Fiander, 2010). Communication between the patient and his/her spouse/partner increases relationship satisfaction when discussing infertility concerns (Woodruff, Clayman, \& Waimey, 2014). According to Shen and Badr (2013), constructive communication increases marital satisfaction, regardless of sexual dysfunction and satisfaction. Cervical cancer patients who opt for FP experience decreased distress compared to those who do not. Because discussions with spouses/partners play an important role in couples' decisions, DAs for making FP decisions should involve spouses/partners.

\section{DAs and Decision-making}

According to the International Patient Decision Aid Standards (2012), "Decision aids are tools designed to help people participate in decision-making about healthcare options. They provide information on the options and help patients clarify and communicate the personal value they associate with different features of the options," and help patients navigate complicated medical decisions. However, they do not replace medical advice, nor do they favor one procedure over another. They collate information and provide various options that are available to patients, but the patient always makes the ultimate decision. An advisor or social worker or other provider can support DAs to help patients make choices. Many medical decisions are complex; providers may not be able to give one right answer to their patients, and these decisions have long-term effects on the patients' quality of life. Patients may have to weigh unknown risks against unknown benefits, and there is no best answer to a problem. The choice a patient makes depends on what $\mathrm{s} /$ he wants in the end. DAs also help provide information to the patient 
and improve his/her satisfaction with the decision made. Most patients are able to choose based on their personal preferences and life goals. However, the decision process is not linear. Patients must consider the advantages and disadvantages of the choices they have made, and DAs may be an important component in the process, together with advice from the healthcare provider, family, the patient navigator, and other hospital staff.

Patient DAs may be delivered in various ways, including pen and paper or digital. The objective of this research was to generate data on the roles of a patient's spouse/partner that may inform development of internet-based DAs for cancer patients. The current definition of delivering patient DAs on the internet is the "...process of using the Internet to provide some or all components of a patient decision aid to help individuals (e.g., patients, caregivers, proxy decision makers, etc.) involved in the process of choosing between two or more medically appropriate healthcare options (e.g., preference-sensitive care)" (Hoffman et al., 2013). Patients may use these DAs at a healthcare facility or from their homes. Choosing a DA begins by collecting initial demographic information about the patient, followed by his/her key goals during treatment; it also provides options along the way. As well as helping the patient, this tool educates him/her about the treatment.

\section{Decision Aids to Help People Who Are Facing Health Treatment or Screening Decisions}

This study in future may inform development of DA's that can be inclusive of Spouse/Partners. According to the International Patient Decision Aids Standards (IPDAS) Collaboration (Elwyn, 2006; IPDAS 2005a; Joseph-Williams, 2013), DAs are evidence- 
based tools designed to help patients participate in making specific and deliberated choices among healthcare options. Patient DAs supplement (rather than replace) clinicians' counseling about options.

There is no single best choice in many treatment and screening decisions. These types of decisions are considered "preference-sensitive" because there is insufficient evidence about outcomes or there is a need to exchange known benefits and harms (Stacey, 2014). Clinical Evidence (2013) classified 3000 treatments as: 50\% having insufficient evidence; $24 \%$ likely to be beneficial; $7 \%$ requiring "trade-offs between benefits and harms;" $5 \%$ unlikely to be beneficial; 3\% likely to be ineffective or harmful, and only $11 \%$ being clearly beneficial. Not only does one have to consider the strength of the evidence, but even for the $11 \%$ that show beneficial effects, it is necessary to translate the probabilistic nature of the evidence for patients to reach an informed, value-based decision. Patient DAs are an intervention that can be used to present such evidence (Brouwers, 2010).

DAs help patients become aware of their choices, understand complex information, make informed choices, and increase satisfaction with decisions. Identifying and making a decision about the best health treatment or screening option can be difficult for patients. DAs can be used when there is more than one reasonable option, when no option has a clear advantage with respect to health outcomes, and when each option has benefits and harms that patients may value differently. DAs may be pamphlets, videos, or web-based tools (Stacy et al., 2014). They provide clarity in making decisions by listing all the options and helping patients understand their choices and their advantages and 
disadvantages. They also help personalize the decision-making path and lead to making shared decisions with their practitioner.

Many studies have demonstrated that DAs are an important tool in shared decision-making, which is defined as a process by which a healthcare choice is made by practitioners together with the patient (Charles, 1997) and is said to be the crux of patient-centered care (Weston, 2001). The four major tenets of shared decision-making are that: 1) it involves at least two participants; 2) both parties (physician and patient) take steps to participate in the process; 3) information sharing is a prerequisite, and 4) a treatment decision is made with which both parties agree (Charles, 1997).

Stacey et al. (2014) reviewed 115 studies from June 2012 to 2014 that included 34,444 participants, and found that when patients use DAs they: "a) improve their knowledge of the options (high-quality evidence); b) feel more informed and more clear about what matters most to them (high-quality evidence); c) have more accurate expectations of possible benefits and harms of their options (moderate-quality evidence); and d) participate more in decision-making (moderate-quality evidence).” To accomplish this, patient DAs may describe the options in sufficient detail that clients can imagine what it is like to experience their physical, emotional, and social effects, and/or guide clients to consider which benefits and harms are most important to them (Stacy et al., 2014).

DAs are more comprehensive than are the usual educational material provided to patients. DAs are based on principles of shared decision-making and empower patients to take ownership of their decisions by participating more in the decision-making process, 
while standard educational materials help people understand their diagnosis, treatment, and management in general terms. DAs can be used before, during, or after a clinical encounter to enable patients to become active, informed participants. The ultimate goal of patient DAs is to improve decision-making to reach a high-quality decision.

\section{Role of social workers in oncofertility decisions}

Oncology social work is the primary professional discipline that provides psychosocial services to patients, families, and significant others who are facing the effects of a potential or actual diagnosis of cancer. The scope of oncology social work includes clinical practice, education, advocacy, administration, policy, and research. The standards of practice provided in the AOSW Oncology Social Work Standard of practice are intended for clinical social workers practicing in the specialty of oncology social work (“AOSW Oncology Social Work Standards of Practice," 2012).The scope of practice in oncology social work identified in the AOSW Standards of Practice includes:

- Oncology social workers shall be knowledgeable about oncologic diseases and their treatments, psychosocial implications for individuals and families, appropriate interventions and available community and governmental resources. Oncology social workers must have knowledge of the usual course of cancer and its treatment, including genetics, so that patients and families can be helped to anticipate and deal with changes in individual and family life.

- Services to cancer survivors, families, and caregivers through clinical practice providing comprehensive psychosocial services and programs through all phases of the cancer experience, including knowledge about cancer and its treatment, 
including level of understanding, characteristics of the patient's support system, patient and family psychosocial functioning, including strengths, limitations and coping skills, race, ethnicity, religion, culture, language, physical or mental disability, socioeconomic status, sexual orientation, and gender identity or expression, and identification of barriers to care.

- Services to institutions and agencies to increase their knowledge of the psychosocial, social, cultural, and spiritual factors that affect coping with cancer and its effects, and to ensure provision of quality psychosocial programs and care.

- Services to the community through education, consultation, research, and volunteering to use, promote, or strengthen the community services, programs, and resources available to meet cancer survivors' needs.

- Services to the profession to support the appropriate orientation, supervision, and evaluation of clinical social workers in oncology; participate in and promote student training and professional education in oncology social work, and advance knowledge through clinical and other research. ("What Are Social Workers' Roles in Oncofertility?”, 2015)

A study by King et al. (2008) found that social workers typically do not discuss FP methods with patients; however, they may be in an ideal position to facilitate the conversation between the physician and patient. There is a strong need to develop educational interventions that target oncology social workers to help facilitate discussions with patients. Oncofertility consultation falls within the scope of oncological social work. 
This study will help oncological social workers provide knowledge that may be applied in the specialty field of oncofertility consultation. 


\section{Chapter 3: Theoretical Framework}

This research focused on couples' FP decision-making process. The study was grounded in the recognition and understanding of power/influence dynamics among couples making a decision. The way one partner influences the other's decision can provide insight into the entire decision-making process. Behavior exchange theory is a key theoretical framework that addresses this process among couples.

\section{Behavior Exchange Theory}

This theory elucidates the decision-making process of couples in various kinds of relationships. Behavior exchange theory (BET) proposes that social behavior and couples' decision-making is the result of an exchange process (John et al., 1976), the purpose of which is to maximize benefits and minimize costs. According to this theory, people weigh the potential benefits and risks in social relationships. When the risks outweigh the rewards, people terminate or abandon a relationship. This framework may be helpful in understanding the exchanges negotiated between couples that lead them to make the complicated decision to engage in FP. According to BET, couples weigh the potential benefits and risks of a decision together, and their decisions are based upon their mutual and complementary goals. Resource theory, an extension of BET, states that the partner who has more resources will have more power in decision-making. According to this theory, an individual's personal resources relative to those of others are the basis of that power. Relative income, education, time available, and social status are examples of factors that contribute to power (Belch, 2002). This theory will help us understand who has the greater say in making a decision. 


\section{Social Power Theory}

Social power theory (SPT) is another theory to consider. According to Raven, Centers, and Rodrigues (1975), there are six bases of conjugal power from the perspective of social power (Belch, 2002). Social power is “...the potential influence of one person over another" (Cartwright \& Zander in Swasy, 1979, p. 316). Thus, power is the total possible change that one social agent can cause in another's attitude, behavior, and beliefs (Swasy, 1979). The six bases of conjugal power are: reward; coercive; referent; legitimate; expert, and information power, and this theory is used to understand the way one partner in a couple may influence the decision of another.

Expert power - the belief that one family member has superior knowledge or ability that will result in the best outcome possible - was found to be particularly relevant to family decision-making. The attribution of expert power was shown to increase with education and social class and with more syncretic decision-making (Belch, 2002). This facet of the theory may apply in this situation, as the male spouse may consider that his partner is the best person to make the decision, as having and raising children primarily are her responsibilities.

However, one cannot rule out such other bases as coercive or reward power, which means that one may either punish or reward the other person while making FP decisions. Information power stems from logic and reasoning and the importance of knowledge and communication. The roles of the provider, DAs, and other information factors may influence couples' decision-making. This may be followed and influenced by 
expert power when one couple or, in the case of FP decision-making, the "provider," may be considered an expert.

\section{Theory of Planned Behavior}

Another theory that may predict health behavior is the theory of planned behavior

(TPB), which has been used widely to predict and explain a range of health behaviors and intentions, including health services use, among others. TPB states that behavioral achievement depends on both motivation (intention) and ability (behavioral control). The three components of the theory, attitude, subjective norms, and perceived control, may predict such patient fertility intentions as having one, two or three children, having children after a certain age, or having children with a partner (Ajzen \& Klobas, 2013). For example, attitude can be measured by such behavioral beliefs as "I want to have a child, as it is fulfilling or would please my partner." Subjective norms may influence fertility, e.g., "My parents or in-laws want me to have children” (Ajzen \& Klobas, 2013). To a greater extent, attitude is a person's internal choice, while subjective norms are attributable to external influences and pressures. Perceived control beliefs are concerned with resources and obstacles that can facilitate or interfere with having a child. For example, one may consider the importance of housing in having a child. It would be relevant in such a case to know how important it is to a patient to have housing before having a child (Ajzen \& Klobas, 2013). Thus, TPB was relevant in this research.

\section{Theory of Attribution, Marital Satisfaction, and Dyadic Interaction}

To understand couples' decision-making, theories of attributions and marital conflict were considered to develop the interview questions. The goal of the study was 
not only to examine the couples' overt expressions while discussing their FP decisions, but to understand such covert variables as beliefs about children, adoption, etc.

Couples' communication exchanges depend not only upon the way a message is delivered to the spouse/partner, but also what attributions the receiving spouse/partner assigns to that communication (Bradbury \& Fincham, 1990). Systematic study of the attributions couples assign to their communication and that of their spouses is believed to explain and enrich the understanding of patterns of behavior exchange that differentiate distressed from non-distressed couples (Bradbury \& Fincham, 1990). For example:

The common tendency in distressed marriages for a negative behavior of one spouse ("You really should be more pleasant around my parents") to be followed by a negative behavior by the partner ("Don't tell me how to behave!") may be due to the attribution that the partner makes for the spouse's behavior (“'He bosses me around because he doesn't care about me or my feelings"). (Bradbury \& Fincham, 1990, p. 3)

To understand the relation between attributions and marital decisions better requires consideration of the behaviors that spouses exhibit and the attributions they assign during interactions. Explicit consideration of overt behavior in relation to attributions and marital decision-making may be justified and explained further by its potential to understand attribution and marital communication in a dyadic communication study.

Borrowing the basic concepts of this theory, this study designed the interview to accommodate dyadic interactions through couple interviews, including questions that 
explored what spouses attribute to patients' feelings. For example, one of the questions included in the research was, "How important is it to you that your partner be able to have her own biological child in the future?"

These theories explain the decision-making process among couples and provide a basic framework; however, their applicability in such a medical decision as FP is unknown. Factors that include unknown risks, an uncertain future, and family and cultural pressures may change the way a couple interacts and makes decisions about FP. The Ottawa Decision Support Framework (ODSF) is a theoretical framework that may help explain processes and contributing factors involved in spousal interactions fully, the various characteristics that lead to a decision, and reflections after a decision is made.

\section{The Ottawa Decision Support Framework}

The ODSF and underlying decision-making theories in psychology, behavioral science, and economics formed the conceptual framework for this study. The ODSF is an evidence-based, practical, mid-range theory to guide patients as they make health or social decisions. It uses a three-step process to:

1. Assess client and practitioner determinants of decisions to identify decision support needs

2. Provide decision support tailored to client needs using counseling, decision tools (patient DAs, guides), and decision coaching

3. Evaluate the decision-making process and outcomes

The framework is based on concepts from general psychology (Tversky \& Kahneman, 1981), social psychology (Ajzen \& Fishbein, 1980), decision analysis 
(Keeney \& Raiffa, 1976), decisional conflict (Janis \& Mann, 1977), social support (Norbeck, 1988; Orem, 1995), and economic concepts of expectations and values (Feather, 1980), all of which it applies to provide a framework to explain the complicated process of making healthcare decisions.

The ODSF framework can be used as a guideline to study couples' decision conflicts by examining the support they receive and their satisfaction with the decision. These tenets guided the research study. Findings from previous literature suggested that this framework has been used in the past to study other medical decision-making (Légaré et al., 2006). 
The original framework includes the following points:

(Figure 1 at page 91)

The framework in Figure 1 provides a process that facilitates shared decision-making. It describes key concepts and was adapted from the ODSF.

Couple decision-making is part of shared decision-making, and this model informed and was adapted for this study.

This theoretical framework will help facilitate understanding of the following areas:

\section{Couples' process of making FP decisions}

2. Effect of marriage/partnership on the way couples cope with infertility problems and treatment

3. Spouse/partner involvement in the entire process of oncofertility consultation

4. Couple's ethical and legal concerns about FP

The ODSF may help couples traverse a structured process of shared decisionmaking. The ODSF helps identify decisional conflict, which is one of the key elements in making decisions (Légaré et al., 2006). Decisional conflict can be described as a state of uncertainty about which course of action to take when the choice among competing actions involves risk, loss, regret, or a challenge to personal life values (Carpenito-Moyet, 2006). This study investigated couples' characteristic views on the types of difficult decisions patients face, the factors that make those decisions difficult for couples, the support couples received in making difficult decisions, and their satisfaction with their decisions. 


\section{Chapter 4: Research Questions and Methods \\ Research Questions}

This study was designed to explore the FP decision-making process from a heterosexual couple's perspective, and the roles of spouses/partners in decision-making by examining specifically their attitudes, behaviors, beliefs, strategies, and the support

they seek and provide to patients during FP decision-making. The goal was to gather data about their perceptions and experiences while making shared decisions with their spouses/partners to obtain a deeper theoretical understanding of which elements are important in addressing FP decision-making and help identify which strategies/approaches are effective in supporting couples throughout the process. Thus, the following research questions were investigated:

1) What is the effect on spouses and conjugal life of potential infertility among young patients with cancer?

2) How do heterosexual couples reach FP decisions?

3) How does being in a marriage/partnership affect the way they cope with infertility problems and treatment?

4) How can spouses/partners be involved in the entire process of oncofertility consultation?

5) What are spouses'/partners' ethical and legal concerns about FP?

6) What recommendations do couples have for those going through similar situations and about ways to promote the importance of fertility treatment?

\section{Methods}




\section{Research Design}

\section{Grounded Theory}

Grounded theory is "the discovery of theory from data" (Glaser \& Strauss, 1967). Theory develops from meanings, actions, stories, and the lived experiences the data reveal. Grounded theory does not begin with a theory or hypothesis and is not designed to prove anything right or wrong. It begins in an area of research and considers data as they emerge (Merriam, 2002). Grounded theory sees beyond research and empirical processes and delves into the data deeply to "portray a picture of [the] whole" (Charmaz, 2006).

Grounded theory is a useful method when there is little or no knowledge available in a particular area, and few studies have explored the effects of potential infertility when one partner has cancer. This study investigated the unique experiences of the spouses/partners of those who are undergoing cancer treatment and may experience infertility. The theory also is useful when attempting to understand the way people define and experience situations within a particular context.

Grounded theory is assessed by fit, understanding (workability), generality, and modification (Glaser \& Strauss, 1967). A theory’s fitness means that it should correspond to the place or field in which it will be used. According to the workability or understanding standard, laypersons should be able to understand the theory. The generality assessment seeks to ensure that the theory is sufficiently general to apply to more than just one specific situation. Finally, modification is assessed by the ability to be flexible in altering or changing the theory as situations change over time (Glaser \& Strauss, 1967). This exploratory study used grounded theory to examine the roles and 
experiences of the spouses/partners of patients undergoing cancer treatment in making FP decisions, the way potential infertility affects a couple's relationship, and the way healthcare providers can support the couple in making shared decisions. The results of the study were compared to existing theories in the field of couple decision-making.

Although theory is emergent and derives from the data (Crotty, 1998) in grounded theory, the theory is open to the results of other empirical studies. The ODSF is an established framework in the literature that addresses decisional conflict. The themes about couples' FP decisions emerged from the data themselves and were incorporated in the ODSF. This was attempted considering the audience and purpose of the research. ODSF is an established framework used when constructing DAs and educational material. This study attempted to test the themes that evolved and whether they fit the framework. According to Charmaz (2006) "One might stumble upon a theoretical framework and can use it to provide an anchor to the reader and to demonstrate how your grounded theory, refines, extends, challenges or supersedes extant concepts.” This framework was used in post-facto data collection during data analysis.

Credibility includes appropriate familiarity with the data, becoming familiar with other comparison groups, and providing evidence for claims the researcher makes. Originality refers to data that provide new insight about their meaning or challenges that exist already. Resonance refers to a researcher's posture of openness and receptivity to the potential meanings embedded in text. I used resonance in this study by associating couples' general decision-making to their specific FP decision-making process. Usefulness indicates that data are interpreted accurately, implications are offered, and the 
study contributes to understanding (Charmaz, 2005). I demonstrated usefulness by addressing issues of trustworthiness and rigor.

The study used purposive sampling, individual interviews with the spouse/partner, and joint interviews with the spouses/partners and patients.

\section{Sample}

Participants were heterosexual male spouses/domestic partners of young adult women undergoing cancer treatment at MD Anderson Cancer Research Center who were at risk for infertility related to cancer. Spouses were defined as legally married couples, while partners were defined as two adults living together. The inclusion criteria for a domestic partnership included:

- 18 years or older

- Unrelated biologically

- Living together

- Not currently in a domestic partnership, civil union, or marriage with a different person

- Mutually responsible (fiscally and legally) for each other

- In an intimate, committed relationship of at least six months' duration

\section{Sampling and Recruitment}

This study used purposive sampling to recruit domestic partners of patients undergoing cancer treatment who agreed to be interviewed for the study. The total sample was 24 individuals. 12 couples were interviewed together and their spouses/partners were interviewed separately thereafter. This study investigated a broad range of the 
experiences of spouses/domestic partners of these patients in different decision-making situations and related the findings to FP decision-making. The interviews included two parts of 45 minutes each. One was the joint interview of the patient and the spouse/partner and the other was with the spouse/partner alone. This dissertation was conducted in collaboration with MD Anderson Cancer Center to enroll participants, and was a subsection of a larger ongoing project. A study coordinator asked the couples who came in for fertility treatment if they were willing to be interviewed together. If the patients and their spouses/partners agreed, then they were mailed a consent letter. The interviews were conducted by phone so that the couples and spouses/partners could talk about their experiences in the comfort of their homes or offices and were scheduled at times convenient for them. Telephone interviews also allowed patients from out of town to be accommodated in this study. The study researcher explained the purpose of the study to participants using clear and plain language, and gave the participants the opportunity to ask questions. The participants were informed that they could withdraw from the study at any time. The study was approved by the PSU Institutional Review Board (IRB) and the MD Anderson Cancer Research Center IRB.

\section{Data Collection}

Individual interviews with the spouses/partners (see Appendix A for interview guide) and questionnaires were used to explore the research questions. There also was a conjoint interview with the patient. First, the couples were interviewed over the speaker phone. After the 45-minute couple interview, individual interviews were conducted with the spouse/partner. If the participant had questions, the researcher clarified and ensured 
that the participant understood the questionnaire, which was administered before the interview began. The researcher transitioned into the semi-structured interview using questions developed in the interview guide, which included specific questions with respect to their relationship with spouses/partners, fertility issues, and the process of decision-making, including follow-up questions based on each participant's responses. The telephone interviews were recorded with a password-protected iPhone. Data were transferred to a secure location, and interviews were deleted from the phone thereafter. Interviews were transcribed and saved in the drop box.

\section{Dyadic Interviews}

According to Morgan et al. (2013), dyadic interviews “...offer opportunities when the researcher wants both social interaction and depth, when narrative is valued, and when interaction in larger groups might be problematic because research participants are geographically distant." Dyadic interviews help the researcher understand tacit knowledge and elicit data in the depth and detail available in individual interviews and, at the same time, provide the interaction present in focus groups while making decisions (Morgan et al., 2013; Polak \& Green, 2016). Joint interviews are a particularly appropriate method for studying complex shared practices such as making health decisions (Polak \& Green, 2016).

Joint interviews may appear to be like everyday conversation, but couples do put on a performance during interactions (Polak \& Green, 2016). According to Warin et al. (2007), participants' responses in the interview are shaped by the positioning of the interviewer in relation to the research. 
Dyadic interviews offer shared storytelling and con-construction of their knowledge. Being asked about their stories from the time they were diagnosed to when they learned about infertility may elicit two things in couples: 1) whether they agree adds credibility to the story, and 2) their storytelling also may hint at the power dynamics between the two. Contradictions found in the stories, if any, help indicate their differences and may provide insight into their relationship, which on the surface may seem non-distressed. This also is associated with the attributions the couples may project to each other's responses. Again, this is a process that may provide insight into a couple's relationship and decision-making process. An important aspect that may emerge during dyadic interviews is the negotiation that couples go through while making decisions. They may challenge each other during the interview, and it is informative to observe who prevails.

Dyadic interview techniques were used to combine and contrast the individual spouse/partner and couple interviews to obtain a better understanding of their decisionmaking process (Koren, 2010). As the literature suggests that the dyadic interview technique is useful in generating discussion with less moderation, it helped elicit deeper discussions between couples. Data saturation was ensured when no new information, categories, or themes emerged from the data. Participants' quotes that highlighted various themes were used to illustrate the data and structure the presentation of the qualitative findings.

\section{Data Analysis}


The qualitative data were analyzed based on the methodology of grounded theory. The grounded theory data analysis approach helps generate themes from the data gathered about spouses/partners' experiences while making fertility decisions with their patient partners. Through grounded theory, I attempted to develop a theme that represented spouses/partners' experiences, including joint family planning with the patient, financial decisions about treatment, and preferences and wishes while making FP decisions. By using grounded theory, an attempt was made to understand spouses/partners' varying experiences in making FP decisions based on different relationship statuses, individual styles, and relevant issues. The participants were encouraged to tell their stories regarding the diagnosis and how they were making fertility decisions. Findings from this research will be instrumental in providing an understanding of the spouses/partners' experiences during the FP decision-making process, as well as in developing standards of practice and policy within the healthcare system and clinical practice. NVIVO software was used to analyze data.

\section{Steps in data analysis}

Techniques developed by Strauss and Corbin (1990) were used to analyze the data:

1) First, five interviews were transcribed and analyzed to prepare a codebook

2) After the first five interviews, additional codes were added as reflected by the data

3) Theoretical memos were written and open coded as data were collected

4) Themes were developed 
5) Themes were mapped visually

6) A literature search was performed post facto to understand similar models

7) Themes were arranged in the ODSF

\section{Establishing the Credibility of Research}

The research results and themes were discussed with a clinician, psychologist, and another researcher involved in the larger study. Peer debriefing also was conducted to establish the credibility of the research. Debriefing was conducted with those who are working directly in the field of oncofertility in the capacity of onco-gynecologists or psychologists/researchers and are in contact with patients engaged in FP decisionmaking. The results were shared with these researchers and their feedback was discussed. Because the researchers were involved closely with patient interviews and developing DAs for patients, they have expertise in the area.

The second method used was triangulation. The qualitative data from patient interviews were compared to those from the couple interviews. Although patients interviewed in couple interviews differed from those interviewed for the individual patient study, the emergent themes did indicate similar results with respect to patients' values and preferences in the larger study (Woodard et al., 2017). For example, both studies indicated patients' desire for biological children, concern for their future health, starting treatment, and ethical and moral dilemmas.

\section{Researcher's Position}

I am the spouse of a cancer patient in remission and also have worked with cancer patients in my previous research. Further, I am aware that being the spouse of a cancer 
patient in remission may provide an "insider's" perspective. However, infertility attributable to cancer was an area of exploration completely new to me. I compared couple interviews with individual spouse interviews to establish the reliability of the findings. Moreover, the findings were compared to other research performed in the field to establish credibility, and I used a journal to document my thoughts and reflections throughout the research process.

I received background information about the couples from their fertility clinics, and in most cases was aware of their type of cancer, age, and relationship status. This initial information about the couple helped begin the conversation with them. I opened most of the interviews by explaining the purpose of the study and disclosing my status as the spouse of a cancer survivor to make them comfortable and ease them into the conversation. Most interviews began with easy to understand questions about relationships before moving into complex relationship questions. 


\section{Chapter 5: Results}

Twelve couples were interviewed first together, after which the spouse/partner was interviewed separately. Couples included both married and cohabitating couples. At the time of the interview, the couples had participated in at least one fertility consultation and had been to a FP clinic. These couples were contacted through the fertility clinic to participate in the study.

The paragraphs below provide general descriptions of the couples from the data collected in the initial demographic questions, which are shown in Table 1. Visual relation of the themes are shown in Figure 2.

(Table 1 at page 88 and Figure 2 at page 92)

\section{Couples' Descriptions}

\section{Couple 1}

This is a Caucasian Christian couple in their early 30s with a 2-year-old child. They are married and living together, and were in their relationship when the woman was diagnosed with cancer. Both hold bachelor's degrees. They did not have a fertility consultation when first diagnosed, but did so at a later stage. They described their relation as not stressed and indicated that they want to have 2-4 children.

\section{Couple 2}

This is a Caucasian couple in their mid-30s with one 2-year-old child. They were married and living together when the woman was diagnosed with cancer. The wife has a bachelor's degree and the husband an MBA degree. They want to have 3-4 children 
together. They described their relationship as not stressed and stronger because of what they have gone through together.

\section{Couple 3}

This is a nondenominational Christian, Hispanic couple. The wife is obtaining a master's degree and the husband a bachelor's degree. They were in their mid-30s and were married when the wife was diagnosed with cancer. Their first fertility consultation took place 3 years after the diagnosis when the couple was trying to conceive. The wife was pregnant when they first went for the consultation but did not know it, and the pregnancy had to be terminated because it was ectopic. The husband has a daughter from a previous relationship and they have no biological children together.

\section{Couple 4}

This is a Caucasian, Protestant Christian couple in their early to mid-40s. They are married and living together. At the time of the interview, the wife was expecting their first child. They want to have another child, but because of the wife's age, the husband thinks they may adopt. Both have an associate's degree.

\section{Couple 5}

This is a Caucasian, Unitarian Christian couple in their early to mid-40s. They both have doctoral degrees and are married. They have one biological child together. They want to have one more child, but because of cancer treatment, feel it is safer not to have more.

\section{Couple 6}


This is an African American couple in their early 30s. The man is an atheist and the woman undecided. Both have Juris doctoral degrees. They now live in two different cities and are unmarried but are in a relationship, and were in relationship when she was diagnosed with cancer. The woman had the first fertility consultation alone. The couple is in a non-stressed relationship and they are undecided whether they want to have children together in future.

\section{Couple 7}

This is a Caucasian, Christian couple in their mid to late 30 s. They are in a relationship but unmarried. They do not have any children but would like to in future. They both have bachelor's degrees and define their relationship as non-stressed.

\section{Couple 8}

This couple is one in which the woman is in her late 20 s and the man in his early 30s. They are unmarried and live together. The woman is an Hispanic Catholic and the man a Caucasian Presbyterian. The woman is working toward her master's degree and the man has a bachelor's degree. Their relationship is non-stressed. The woman would like to have 3 children and the man 2-3 children. They have no children now.

\section{Couple 9}

This is a Caucasian, Christian couple in their late 20s. They both have bachelor's

degrees. They are married and live together. They have an 8-month-old daughter and would like to have at least two children.

\section{Couple 10}


This couple is in their mid to late 30s. The wife is Asian and the husband Caucasian. Both are Christians. The wife has a bachelor's degree and the husband has no college degree. They have no children together but would like to have at least two.

\section{Couple 11}

This is a Caucasian, Christian couple in their early to mid-30s. They are married and have two children together. They would like to have one more child in future. They have a non-stressed relationship.

\section{Couple 12}

This is a Caucasian, Christian couple in their early 30s. They are married and have bachelor's degrees. They have no biological children together or separately. Their current relationship is non-stressed, but they had some stress in the early years of marriage. They want to have 2-3 children in future.

\section{Interview Findings}

The 12 qualitative interviews were coded and analyzed to address the research questions. The analysis included three parts. First, only the couples' section was analyzed. Significant sentences and quotes were highlighted to understand the decisionmaking phenomena. In the second part of the analysis, the spouses/partners' section was analyzed to obtain a better understanding of what the spouse/partner was experiencing.

The purpose of the first part of the analysis was to understand the joint decisionmaking process and the way it differs from other decisions the couple has made. In the second part, only the spouses/partners' section of the interview was analyzed to understand their viewpoints on FP. 
In the first part of the analysis, codes were organized into the following themes:

1) Couples' relationship and decision-making

2) Couples' response to the news of potential fertility loss

3) Couples' general decision-making process versus FP decision-making

4) Legal and ethical concerns

In the second part of the analysis, only the spouses/partners' sections were analyzed and compared:

1) Spouses/partners' reactions to infertility

2) Spouses/partners' views about biological children

3) Spouses/partners' concerns

4) Support

5) Recommendations for couples in a similar situation

The third part of the analysis entailed comparing both sections of the interviews and looking for shared storytelling:

1) Confirmation/collaboration within couples

2) Contradictions or differences in narrations

3) Differences in spouses' versus couples' narrations

\section{Couples' Section}

\section{Couples' relationship and decision-making}

Couples differed in their opinions about what was most important to them in making decisions in their relationship. Couples 3, 11, and 12 reported mutual satisfaction, couple 10 indicated willingness to compromise, couple 9 stated mutual agreement and 
communication, couple 8 reported communication and analyzing pros and cons, couple 7 emphasized shared communication, couple 6 indicated mutual satisfaction and fairness without compromising values, couple 5 reported decisions with no regrets and from which no one walks away, couple 4 stated that it should fit the larger goals as a couple and person, couple 2 indicated logical decisions with fewer risks, and couple 1 reported that decisions should be in favor of who feels more strongly about them. Hence, couples decision-making priorities differed. The most common was mutual satisfaction, in which both were in some way comfortable with the decision. Communication during decisionmaking was important for the couples. Some mentioned making a list of pros and cons, while others mentioned going on dinner dates to discuss important decisions.

\section{Couple 3}

Patient: "I think mutual satisfaction. Not only does that fall in line with communication amongst each other as well. As long as we communicate and agree. Even if we disagree we are able to come to a final resolution that makes both of us happy. If it makes one happier than the other, then that is fine with the both of us."

Spouse: "I think for me it is more important that we both are okay with the decision in the end, that neither of us has any regrets about the decision."

Patient: "Sure, I don't want either of us to walk away from a decision, especially a very important decision, having any regrets about our decision process or the outcome of the decision."

The Spouse in couple 4 stated that, "One is we are going to know what we are talking about and how does it fit into our goals, our personal goals." 


\section{Couples' Response to the News of Potential Fertility Loss}

Women and men reacted differently to potential infertility. For example, one of the patients during a couple interview shared that she felt more deeply about the issue of not having children than her spouse did.

\section{Couple 4}

Patient: "He was okay without them (children), and at that point I still wasn't okay without them. I felt that I wasn't going to get to be a mom."

Spouse: "Because for me, just from my perspective and how it was, because as a man I was reaching my goals, doing things that caused me to be satisfied as a man. I didn't think that I had to have children to feel fulfilled in life. So, I didn't understand."

Some of the spouses were more concerned about their partner's health than infertility, but women took more aggressive steps in obtaining fertility treatment.

Patient 1: "Well, no, actually. At first-since I had gone through cancer and everything, he really did not want to do any type of fertility treatments where it would affect my body. He didn't want to put any hormones or anything. He didn't want me to have any struggles or health problems or anything again. I actually had to talk him into going and meeting with Dr. XXX. Once he talked to her, he felt much better about it."

One of the couples had to make a quick decision between the time of the cancer diagnosis and fertility treatment; hence, they felt helpless in the situation, as they did not have much time to process the news of infertility.

Patient 2: "I feel we were kind of just thrown into it, similar to other medical decisions. Given that I was about to start chemo and they didn't want to delay it. Again, it 
was a very rushed decision and I think we kind of knew what we knew and didn't know what we didn't know."

Another woman was willing to bear more pain rather than risk infertility.

Spouse 3: "She just didn't want to have the kind of surgery to prevent her from ever having kids, no matter how much pain it put her in."

Hence, the data suggested that women were far more invested in pursuing FP than were their spouses/partners.

\section{Couples' Process in Making General versus FP Decisions}

During the interview, couples were asked what is important for them in making decisions and the way the FP decision differed from similar and other major decisions. Couple 1 agreed that they let the partner for whom it is more important take the lead in the decision.

Spouse 1: "Some things are more important to one or the other parties. So, if it is more important to me, [wife] will let me decide. If it is more important to [wife], I'll kind of let her decide."

In couples' fertility decisions, Spouse 1 indicated that he followed the same motto.

Spouse 1: "In terms of fertility treatment itself, I kind of defaulted to [wife], I guess, a little bit with that because it was her body that was going through everything." Couple 2 responded along similar lines that the person who is affected most by the decision should make it, and because FP affects the woman's body, the decision was hers. 
Couples 3 and 6 believed in mutual satisfaction.

Patient 3: "As long as we communicate and agree."

Couple 4 disagreed about the issue of FP.

Spouse 4: "How does decision fit into our goals, our personal goals? If it is a major decision, how does it fit into life goals? Then from there, I would think then we would see and discuss how important it is to each other."

With respect to making the FP decision, this couple disagreed, as the husband was not in favor of having children after trying natural methods for seven years. The wife mentioned that after they visited a marriage counselor, he understood that it is a "woman's nature to have a child, that's when everything turned around." Hence, the couple reached a compromise after they understood each other's life goals.

In conclusion, couples' FP decision-making was consistent with what they said was important for them in making any other decision.

\section{Legal and Ethical Concerns}

There were several religious concerns, including destroying preserved embryos.

Husband 12: "I think the only thing that I was a little, religiously a little concerned about was that they recommended saving, if we had harvested eggs, they wanted to save them as embryos, because that was the most efficient way to preserve the eggs and the sperm. I was a little concerned that if we were lucky enough to get multiples

of eggs, we were able to get multiple embryos, would we be able to use it. I wouldn't have wanted any of them destroyed, so a little iffy about that." 
Husband 8: "Maybe a moral decision. I don't know if it is totally moral, just maybe where we are in our lives, knowing that you would possibly make embryos that you would not even use and stuff like that. Maybe more for me personally."

Couple 4 had ethical concerns about terminating pregnancy if a child happened to have special needs and screening embryos for chromosomal abnormalities.

Spouse 4: "I think the biggest concern is a little bit personal, a little bit involved with our faith, is the thought of -it is one we will still face and we thought of if we were told we were going to have a special needs child. What decision would we make at that point? Would we continue with the pregnancy or would we terminate the pregnancy? That is a big issue. That is a big conflict. That is a big decision for us. One of the things that we did, once we did the fertility cycle and we had embryos that made it to the 5-day stage, we had them genetically tested, so that any abnormalities in the chromosomes, anything that might cause the embryo not to be a perfect embryo, we could do that prescreening, so those embryos that would be questionable, we would not attempt to implant. That was a big decision, a big discussion that we had."

\section{Spouse/Partner Section}

\section{Spouse's/partner's reactions to infertility}

Some spouses/partners showed more concern about the patient's health than they did about expressing their emotions/reactions to infertility news.

Spouse 1: "I guess at the time I was really more focused on just her surviving, making it through the chemo. The chemo treatments were really hard on her. So, it was more just wanting to get through. I just focused on what is front of you right now, which 
was get through the chemo treatments, get through beating this portion and then we will worry about the rest of it later."

Spouse 3 expressed shock about the news of infertility, but again showed concern about the patient's health.

Spouse 3: "When I found out about it, it was a shock, but I was more concerned, once again, about her health and her mental stability, because I just know that is something that can devastate a woman, and a man, too."

For Spouse 4, the news of infertility did not matter much but, as it mattered to the patient, he was willing to go through fertility treatment.

Spouse 4: "Like I said, for me I think I would have been okay without having kids, but the thought of not being able to give her what she desired, to fulfill her dreams, was deeply frustrating and deeply hurtful."

Spouse 5 did not view the news as a huge shock.

Spouse 5: "This was not a huge surprise or shocker or concern for us, because, again, it is completely dwarfed by the medical issue. So, there was an acknowledgement but not a lot of emotionality about it. Again, as [wife] said, we weren't planning to have any more kids anyway."

Spouse 7 indicated that although they were prepared for the news of infertility, they were not totally ready for it.

Spouse 7: "Ifelt bad for her because she wouldn't be able to do it, but we knew that there was a chance that she would have that for a while. We were probably a little prepared for it, but not fully." 
Largely, the spouses/partners' reactions to infertility were followed by concern for the patients' health.

\section{Spouse/partners' view about biological children}

When asked how important it is to have biological children, most of the spouses responded that it is very important for them.

Spouse 2: "I think very important. It is important enough that I would kind of do anything to try for that. If that wasn't possible, I would be comfortable with alternatives, but wanted to do what we could to have a biological child that was mine."

However, they expressed the intensity of their desire to have biological children differently depending on their individual situations. For example, if the choice was between the patient's health and having children, the spouses/partners stated that the patient's health was the priority.

Spouse 3: "Yeah, I would love to. It is important to me, too, but on the same token - this is something that basically humbles me, I'm just not wanting to put her in harm's way just for that need. It is important to me, but I just don't want to sacrifice her for that."

Spouses/partners expressed the desire for biological children for family connection, acceptance, and family lineage, and to have children who might have the same talents as the couple.

Two spouses did not express a strong desire but were comfortable adopting instead. 
Spouse 7: "Probably much lower on the scale (importance of having children to him than his partner). I am pretty indifferent about it.

\section{Spouse/partner concerns}

Spouses/partners expressed several concerns about making the FP decision.

Spouse 2 felt that thinking of different scenarios while making FP decisions was depressing.

Spouse 2: "I think the specific ones are kind of being thrown in this situation and now-as I said it was happening very quickly and not really thinking about it, and then all of a sudden being asked the question of, what if one of us dies in some months and you are left with these embryos? Who gets them? What happens if we have a gestational carrier carrying our child and both of us pass away — the depressing scenarios to think about, but certainly forced some interesting-it just required us to think through some things that we really never anticipated and certainly never previously talked about."

Spouse 5 voiced concern about the patient's health rather than FP treatment.

Spouse 5: "Really, the factor that I think you are getting at would be any delay in treatment for [patient] might mean that she is in our lives for that many days fewer. That was just not okay."

Cost as a concern came up once in the interview with Couple 7.

Spouse 7: "Cost was an issue, but we had the money [inaudible] to do it."

\section{Support}


Spouses/partners were asked if they felt they were supported well during the process, and their responses to this question depended on the couples' individual experiences.

Spouse 1 felt supported by the healthcare providers.

Spouse 1: "Yes, we went through-yes, we went with Dr. XXX and she really laid out what the plans were. I made as many of the hospital visits or doctor's appointments. She had ultrasounds. I made as many of them as I could. Although the focus was always on her, I was always asked if I had any questions or if I had any concerns."

Similarly, Spouse 3 felt supported well.

Spouse 3: "Everybody that we have met, they have done a fantastic job. I don't want to say this to make it sound like they didn't do this, but just the most important thing I would suggest is that they just provide the most information about the processes, what the spouse is going through, what the possibilities, the risk factors-information, information, information. Just provide the most information about whatever they feel that need-whatever the discussion, just go into depth on everything, to where they just disclose everything."

Spouse 8: "I think they took care of us very well. They gave us plenty of information, and I like that we had a lot of options. I think they did a very good job."

Spouse 2 related a different experience.

Spouse 2: "I can't think of a certain situation where I felt that I needed independence from [C] supports or different information. I think it would just be the general comment that they just seemed very unaware of the specifics of our unique 
situation. It is not often you go to a medical provider and get a sense that they don't know what they are doing, but we had that sense quite a bit going through that, which was a frustrating circumstance."

Spouse 7 had similar views.

Spouse 7: "I don't know what support and information that she got, but I didn't really get much at all. I would say if I was the average person, probably no."

\section{Recommendations for couples in a similar situation}

Spouses/partners had recommendations for other couples. Spouse 1 addressed the importance of understanding what the patient is going through.

Spouse 1: "I know it was very difficult for her. I guess maybe remind spouses to understand what they are going through, from a hormonal standpoint. My wife put a lot of pressure on herself to have a biological baby."

Spouse 2 addressed the important issue of oncologists' lack of initiative and interest in discussing fertility.

Spouse 2: "I think of the oncologist never being comfortable making a statement to the effect of it's fine for you to go through this fertility treatment. I think from the oncologist's perspective, there was never any good that could come of it, only harm, and very little understanding of how do you weigh the potential risks with the benefit of being able to preserve your fertility with the patients and debating with oncologist may be difficult for other couples. So, having that debate with the oncologist was a very difficult one." 
Spouse 5 said that it is important to have a fertility consultation regardless of the outcome.

Spouse 5: "I think we are both pretty grateful that we went through and had that conversation with experts, even though the outcome was, I think, pretty obvious before we ever met with them. We knew that this was the end of a type of option for us to have in our lives, but it was comforting to know that we would not be looking back at this and second guessing ourselves and we were certainly doing the right thing. It is a big decision, even if it is obvious."

Spouse 7 suggested to go ahead with FP even if there is disagreement.

Spouse 7: "I guess I would just tell them that if they don't agree to do it, they can't undo the decision later, so it is better to probably do it now, and then have the contract, if you want to change your mind later or if it is just eggs, there is not a big change for you, because it is still just an egg like it would be in her anyway."

Spouse 10 suggested finding support.

Spouse 10: "There are lots of things that a couple may not be thinking about, where someone who has gone through the process can share. I actually think it would be a terrible idea not to talk to someone who has been through the process before you decided to go through it yourself."

\section{Couples' Shared Storytelling}

The joint interviews with the couples offered shared storytelling about their diagnosis and decision-making that constructed a coherent and presentable story as a couple. Couples were asked to narrate stories about their critical milestones in decision- 
making. Couples co-presented the story of shared decision-making, and in the process coconstructed their knowledge about their style of decision-making and its application to joint problems. The interviews were analyzed for shared experiences in decision-making (general and FP decisions) to understand the roles of spouses/partners with the rationale that significant others are central to the experience of undergoing treatment, and the relationship between patient and spouse/partner is an important part of analysis. The analysis of these interview narratives was informed by Radcliffe's (2013) methodology of co-construction of illness narratives among stroke survivors and their spouses. The interviews were designed to look for confirmation and contradictions. The confirmations were studied from joint interview sessions, and contradictions were studied in spouse/partner interview sessions to see whether couples challenged each other's ideas as they narrated their stories. Further, contradictions were studied to see whether a spouse/partner's narration differed between the joint interview session and the spouse/partner session.

\section{Confirmations and collaborations in narratives}

As couples narrated their stories, they completed each other's narrations, adding details and reasoning for why they did what they did.

Spouse 1: "She was diagnosed. We didn't have a fertility consultation when she was first diagnosed because they needed to start treatment straight away. They didn't have time to collect eggs or anything."

Patient 1: “And Dr. XXX wasn't there yet." 
Spouse 1: "Yes, Dr. XXX was not at MD Anderson. It wasn't an option. We needed to start treatment."

When asked about their decision styles, most couples agreed with each other's narratives.

Spouse 2: "I would say I am a very logical thinker when it comes to making decisions. If that makes sense we like to talk things through. I wouldn't say that we deliberate very long in most decisions. I think we like to discuss it, make a call on what makes sense and has fewer potential risks around it, and then go ahead and move forward."

Patient 2: "I would say that [W] is the more logical one out of the two of us. I tend to be a bit more emotional, but I think it is helpful be having [W]'s rational side. Sometimes I just let my emotions hinder my decision-making, I think. But we sit down and sort of go over pros and cons and we decide, I guess, mutually."

Couples also agreed as they discussed the way their relationship evolved during decision-making.

Patient 2: "I think for me it is just making sure that I feel supported and that I feel like $[W]$ is an active part in the decision. They are big decisions and they are scary decisions. They are decisions that you don't know a lot about and you don't know the outcome. I think just knowing that he was on my side and that we were in it together again, I just felt like it almost bonded us even stronger than we were before." 
Spouse 2: "I think that's right. I know that it sounds like the easy answer, but I think it was an emotional time, so going through that together was helpful to our relationship generally, being closer in a time like that."

\section{Contradictions in narratives}

Some contradictions were simple and were merely about timelines as the couple recollected the stories about their fertility consultation, treatment, and decision-making.

Spouse 1: "When did we first meet Dr. XXX? Two years ago?"

Patient 1: "No, we had to wait another year. We met 3 years ago."

Spouse 1: "2013? It's a while since we thought about it. We did fertility treatment through the whole of 2014, so 2013? I think 2013."

The exchange above might seem insignificant, but contradictions helped construct more accurate stories and reveal stages in decision-making that one partner may have skipped. In the following example, the patient revisited the timeline and revealed that her spouse did not agree with the FP procedure at first.

Spouse 1: "In terms of fertility treatment itself, I kind of defaulted to [R], I guess, a little bit with that because it was her body that was going through everything. I'm trying to think back."

Patient 1: "Well, no, actually. At first, since I had gone through cancer and everything, he really did not want to do any type of fertility treatments where it would affect my body. He didn't want to put any hormones or anything. He didn't want me to have any struggles or health problems or anything again."

\section{Narrative differences: Joint versus spouse/partner interviews}


Spouse 1 expressed his concern for the patient's health and a desire for children in the couple interview, but during the individual interview he indicated more strongly that he cared much less about having biological children and more about them staying together as a couple.

Spouse 1, individual interview: "Yeah, I've always wanted to be a dad. I've always loved kids, but I think it was less important for me that they were my biological children. It is one of the things I said, when she said, you can leave me, I may never be able to have children. We'll have children together. It may not be our biological even if we have to adopt, whatever, it is fine."

This is what he said during the joint interview:

Spouse 1: "Yeah, because it was going to be her body going through all of it. I said, 'Look, I'll support and do whatever I need to on my side, but it is ultimately your body that is going to be going through all of this, going through all of it, and having the hormones. So, it is up to you. I'll support you and we will do what we need to do."

Spouses/partners also disclosed some information during the individual interviews that they did not at couple interviews. For example, one of the spouses disclosed the patient's desire and fertility challenges even before they underwent the entire cancer treatment.

Spouse 1: "Very important. Yeah, it was really important for her (to have children). She has always wanted to be a mom. She loves babies and stuff, like most people do. Yeah, for her, she had always been concerned, even before the cancer. She only had one ovary so she was always concerned that there may be some problems with 
her having children. It was one of the most important things for her, to be able to have babies."

Spouses/partners were more expressive about their reactions to the infertility news.

Spouse 2: "Yeah, when I accompanied [C] to one of her appointments, I guess maybe her initial appointment when she was first diagnosed, I think that while I had prepared myself that she likely had breast cancer, I don't think I ever realized that that would potentially have repercussions on fertility or starting a family. It never really crossed my mind that that was one of the consequences of going through cancer treatment and chemo. I think when the doctor made a comment, and it was probably even kind of an offhand comment she was focused so much on the cancer diagnosis, I think she just casually said, this probably will mean you won't be able to carry your own children. I think that was a shock to me because I had never, as I said, even thought about that. So, at first when the comment was made, I didn't even realize that there were potential options that we could explore. I don't think in that first meeting that was ever discussed in any detail. As I said, I think it was just a very quick comment and we were already so taken aback by everything else that was going on, we didn't ask questions around that point. It was definitely a very, it is a difficult thing to kind of take when you are going into something not even expecting that is a potential outcome."

In another case, a spouse opened up during the individual interview: 
Spouse 4: "Like I said, for me I think I would have been okay without having kids, but the thought of not being able to give her what she desired, to fulfill her dreams was deeply frustrating and deeply hurtful.” 


\section{Chapter 6: Discussion}

\section{Overview of the Study}

The objective of this study was to explore the roles of spouses/partners in making decisions about FP to inform the development of interventions such as educational material, counselling sessions, DAs, and coordination of care plans that may help couples make informed choices. The discussion explores the way the theoretical framework and results from the study answered the research question. The first section (couple interviews) was conducted to answer the research questions about infertility's effects on couples and conjugal life, i.e., how do couples reach a decision and how do they cope with infertility problems and treatment in their relationship? The second section (spouse/partner interviews) answered the next three research questions: How can spouses/partners be more involved in decision-making, what are the spouses'/partners' ethical and legal concerns about FP, and what are their recommendations for couples going through similar situations?

\section{Couples' Responses to the News of Potential Fertility Loss and Coping Mechanisms}

To understand the response to infertility news, spouses/partners were asked to tell the story about when they first learned about fertility compromise and the way they felt. To achieve a deeper understanding of the way spouses/partners truly felt about infertility, they were asked how important they felt it was to them to have biological children.

In the joint interview, questions related to making FP decisions were answered with their stories, feelings, and emotional struggles about not having children. 
The results indicated that couples felt a sense of loss when they hear the news of infertility. These results were consistent with other studies that have shown that infertility among couples leads to feelings of loss of control, perceived loss of femininity or masculinity, and loss of attractiveness or self-esteem (Oncofertility Consortium, 2013; Schwartz et al., 2010).

Spouses/partners of patients acknowledged the importance of having biological children and several expressed the reasons they wanted to have biological children clearly, e.g. family lineage, passing genes, etc. However, for them, the patient's health took precedence over fertility treatment and they were willing to explore other options. Another large longitudinal study indicated that, in addition to infertility itself, the treatment causes additional distress (Greil, Quillan, Shreffler, 2011). Distress from treatments may explain spouses' concerns and prioritizing multiple treatments (cancer and fertility).

Patients (wives/female partners) were more vocal about how eager they were to have children of their own and their willingness to take aggressive steps to have biological children and pursue FP treatments. Although both patients and spouses are affected by potential loss of fertility, their responses differ. A study of 449 couples in a fertility clinic found that infertile women showed higher levels of distress on a global measure of psychiatric symptoms than did their partners. Women showed more anxiety, depression, hostility, cognitive disturbances, increased stress, and lower self-esteem (Wright et al., 1991). Greater distress attributable to infertility may explain patients' willingness to take more aggressive steps in FP than their spouses. 


\section{Roles of Spouses/partners in FP Decisions}

\section{How do couples reach FP decisions?}

Two aspects of couples were studied to understand spouses/partners' roles in making FP decisions: 1) What is the status of their current relationship? 2) What is the couple's decision-making process?

To address the first aspect, couples were asked if they considered their relationship distressed or non-distressed. Because all couples answered "non-distressed" at the time of the interview, their current relationships of were considered happy and satisfied. Although this may not be sufficient to determine the actual nature of a relationship, it was accepted as stated by the couples. As the literature indicates that couples do put on a performance during interactions, it is possible that some couples may not have responded to this question truthfully (Polak \& Green, 2016).

To obtain a deeper understanding of spouses/partners' roles in decision-making, particularly about FP, questions addressed couples' general and FP decision-making processes and the results were analyzed to compare each member's role in making the two decisions and what they felt was important in their decision-making processes.

Couples were consistent about what they rated as most important in the two types of decision-making. For example, the husband in Couple 1 defaulted to the wife in the case of making the FP decision, as they shared in the interview that the person who is affected most takes the lead in their decision-making overall, and because FP affected the patient's body most, she took the lead. 
Most of the couples shared similar ideas, that if any decision affected one person the most, then that person would take the lead, which, in the case of FP, was the female partner/patient. Hence, in most cases, the spouses agreed that it was the patients' decision, and they agreed with it. This result is consistent with SPT (Belch, 2002). Two bases of conjugal power mentioned in the theoretical framework, expert and information power, may support these results. Because patients are considered the ones who will be affected most by the FP procedures, they are considered to have more knowledge and hence the decisions are deferred to them.

Another strategy of decision-making reported was making pros and cons list. This exercise can be explained by BET. According to the theory, people weigh potential benefits and risks to make a decision (John, et al., 1976). Couples make a decision by considering the benefits of FP and the risks involved, including delay in treatment, costs, and prognosis.

However, one couple had differences of opinion with respect to FP decisions, but again, the patient was able to convince the spouse. Here, the decision-making process may be explained by the TPB, which includes three components: attitude, subjective norms, and perceived control (Ajzen \& Klobas, 2013). Each partner may have different attitudes and subjective norms about having children. In this research, the disagreement stemmed from differences in life goals that led to differences in attitudes about having children. 
Overall, couples decided in favor of the patient's desire and described the process of decision-making as consistent with what they felt was important in their general decision-making process.

\section{Spouses'/partners' concerns and support}

The most common concern among all the spouses/partners interviewed was the patient's health versus FP treatment, in which spouses/partners showed concern about the fertility treatment's effects on the patients. A longitudinal study by Greil et al. (2011) suggested that patients not only experience stress related to infertility, but also elevated stress attributable to infertility treatment itself, and spouses/partners also may experience stress related to such treatment. This area may be explored further to understand the phenomenon among spouses of increased concern about the patients' health and relative concern about infertility treatment.

One of the spouses/partners also mentioned feeling depressed by all the decisions that needed to be made. Infertility and treatment for the same leads to poor psychosocial outcomes (Schwartz et al., 2010), and stress related to decision-making may lead to feelings of depression among spouses/partners.

With respect to support they received from their providers, most spouses felt the providers supported them well and were satisfied with the information they received from them. However, some spouses did share stories of experiences in which they were not attended as per their expectations and had frustrating experiences. A prospective multicohort study conducted with spouses of total laryngectomised cancer patients concluded that it is necessary to support the spouses to help them cope with psychological distress, 
as well as develop treatment plans to accommodate spouses' psychosocial needs (Meyer et al., 2015).

\section{Shared storytelling}

Couples co-constructed their stories as they narrated them. Because they were telling their stories in retrospect, there was a bit of confusion about timelines as one spouse/partner narrated and the other corrected. The effect of hearing the story in retrospect indicated that the timelines were blurred in the couples' minds.

Most of the couples confirmed each other's narratives with respect to discussing their decision-making styles and evolving relationship while making the FP decision. However, the interesting findings of the research were the contradictions and differences in spousal narratives between the joint interviews and individual interviews.

The reasons couples may confirm each other's narratives and project a joint decision-making process may be attributed to social desirability factors to show their relationship in a positive light. Although they may discuss differences in their opinions, they confirmed that they reached agreement in the decision ultimately and weighed similar attributes that were important in their relationship and decision-making.

There were few contradictions regarding timelines and the way each partner took a stand in the decisions, which helped check the credibility of each other's accounts of events.

Differences in narration between individual and joint interviews helped reveal more honest opinions about decision-making. Spouses/partners were more vocal and expressive about the way they truly felt as a caretaker and partner in the decision. 
Although some spouses/partners expressed that they wanted to let the patient decide and would be supportive of their decision in the joint interviews, they did express their concerns, stress, and shock about infertility during the individual interviews. Polak and Green's (2016) study, which stated that couples put on a performance during conjoint interviews, supported this finding. It was in the individual interviews that spouses voiced more intense and honest feelings about the FP decision and their desire for children.

\section{Ethical/Legal Concerns}

No legal concerns emerged from the data. However, couples discussed some ethical/moral concerns during the interviews. These included destroying unused fertilized eggs and making decisions to abort a child who had special needs. Concerns about abortion are beyond the scope of this study. However, concerns about unused fertilized eggs/embryos have been documented in the literature. Patients have voiced their dilemmas about destroying eggs. Clinics throughout the US store embryos but are becoming more aggressive about forcing couples to decide. Couples are given the following choices: Implant the frozen embryos; donate them to other couples; pay the high annual storage fee, or have them destroyed (Ekman, 2015). These ethical dilemmas need to be addressed as we make progress in this field.

\section{Spouses/partners' Recommendations}

Spouses made several recommendations for the providers as well as other couples going through similar situations. Both emphasized the importance of understanding the patients and supporting them throughout the process despite the struggles that they are going through as a couple. 
With respect to FP, spouses/partners highlighted the importance of having at least one FP consultation strongly. One spouse even recommended a FP procedure even in the case of disagreement. This recommendation may be an exception and can be attributed to the individual's personal beliefs and experiences. None of the couples regretted FP or recommended foregoing consultation. They did recommend that oncologists be proactive and more invested in referring patients for fertility consultations. Overall, patients stated unanimously the importance of FP consultation and the advantages of going through the process.

\section{Decision Framework Anchored in ODSF}

The decision framework built from the current research was anchored in ODSF. This exercise was undertaken to understand the way current research can support and inform a standard decision framework in the decision-making field. Charmaz (2006) explained this practice and indicated that after research analysis, we may find a theoretical framework that current studies may refine, extend, challenge, or supersede. This research used the ODSF framework to diagram themes to see whether the data inform the ODSF framework in the context of couples' decision-making.

The way the components of the ODSF framework corresponded to the themes of this research is explained below.

(Figure 3 at page 93)

In Figure 3, Decision needs implies the decision to be made and the characteristics of the decision and decision makers. This study collected the characteristics of decision makers through demographic information, relationship status, 
motivations for decisions (desire for children) and couples' decision-making styles.

Decision quality informs the ethical values that affect the decision and, in the end, who makes the final decision. The Decision support section informs the couples' recommendations to support the decision-making process better. Although there are gaps in the current themes necessary to fill the framework completely, it informs future research in the effort to develop aids and support material for couples' who are making FP decisions.

\section{Recommendations from the study}

\section{Couples' Consultation}

Couples' consultation is vital in providing support to the patients making fertility preservation decisions. As the data suggests that spouses are invested in fertility health of the patients, and they do show remorse to the potential infertility news, it is essential for the providers to listen to spouses' needs for information and emotional support. It is essential to build support system around the couple especially when it is a joint FP decision. Lack of such support may leave the spouses confused and distressed. This may negatively impact overall satisfaction in the FP decision making among young patients.

Even though it may appear to be burden on the healthcare system to provide support to patients as well as spouses through FP decision making, it is essential from the providers' perspective to know spouses' opinion. Spouses may withhold their opinions in front of the patients as seen in the data. Along with couple consultation, separate spouses' 
consultations may openly bring out the honest intentions of the spouses. Hence when providers make FP treatment recommendations they are aware of the complete couple situation. Providers may also encourage the spouses to open discussions with the patients during FP decisions.

\section{Patient and Spouse Navigation}

Oncology social workers also work as patient navigators in the clinics. Oncology social workers not only need to help patients but also their spouses while planning coordination of care for the patients. Patients more likely visit clinics with their spouses/partners. It is essential to actively involve them in the care plan as they are key stakeholders in patients' care. Patients' after treatment do feel exhausted. FP consultations and paper work may be overwhelming for the patients. Involving spouses

may take some of the burden away from the patients, hence improve couples' experience in clinic.

Future studies will be needed to confirm if the above mentioned recommendations improve the quality of care for the young couples making FP decisions thus justifying time and money spent on working with the couples rather than just patients.

\section{Implications for Future Research}

This study addressed a significant gap in understanding couples' decision-making with respect to oncofertility. It was an exploratory study that provides various opportunities for future research in theory development and decision frameworks. More research is required to validate the current relations between themes that emerged in the data. 
First, the study gathered data on couples' decision-making styles and their relation to making FP decisions. This concept may be explored further using psychosocial analysis and surveys with couples to explore the nature of their relationship and the stress they undergo while making FP decisions.

Second, the research offers opportunities to refine the themes and concepts that emerged from the data further, for example, couples' responses to the infertility news. It also is possible to explore various components of their responses in further detail. Researchers may time the interviews after breaking the news and collect data by videotaping and recording the couples' discussions. Other themes, for example, the need for biological children and spouses' attribution about the way the patient feels about having children also may be explored in future research.

A longitudinal study could be conducted that follows couples from the time they learn that their fertility may be compromised to when they make a choice and a year thereafter to collect data on their satisfaction with their FP decision.

Finally, as stated in the limitations, this research was limited to non-distressed relationships and heterosexual couples. Further research with same-sex couples and those that may be in distressed relationships can increase our knowledge about this complicated decision-making process further.

\section{Implications for Oncofertility Clinical Practice}

This study will inform the oncofertility practice as it tries to develop couples' interventions, including FP DAs for patients, clinical practices, couples' counseling, and other similar support for patients who are making FP decisions. Oncology providers may 
invite women to consider their spouse/domestic partners' roles and potential needs during their introduction to FP. For example, they may introduce the concept of deciding who will be involved in the deliberation process versus who will be involved in making the final decision. Similarly, fertility specialists may wish to advise women to invite their spouses/partners to attend the FP consultation, and assess the desired roles and informational needs of the couple and each individual purposefully. Results from this study may inform the design of a DA that tailors information and decision-making support to women and their spouse/domestic partners. DA developers may wish to assess whether the themes couples identified in this clinical context apply to their clinical context. These findings may help support high-quality decision-making for each individual and enhance further the quality of couples' informed consent consistent with the legal and policy requirements for many FP therapies. As efforts continue to create certification criteria for patient/family DAs, additional criteria may be needed that address the roles and needs of couples making decisions specifically.

The study also recommends that clinicians counsel couples when they contact fertility clinics. The focus of the counseling certainly always will be on the patient, but spouses/partners need support and information, too. Understanding the needs and wants of patients' spouses/partners and addressing both is critical in providing holistic care to the patients.

\section{Implications for Social Work Practice}

As social workers, we are trained to attune ourselves to the clients' environment and understand their family support to provide adequate help. In the case of FP, spouses/ 
partners are a significant element of this environment. This research informs social workers about the complications associated with making FP decisions and directs them to plan interventions for the couple as a whole. They also serve as liaisons between different institutions and help couples collaborate with various providers while making FP decisions. As the literature review stated that social workers may be navigators for oncology patients, because they are working through the case and helping patients with their options, this research informs them about the process and interactions between couples as they make FP decisions. Social workers need to be mindful of the fact that, although the patient may be the primary decision maker in most cases, spouses do play a supportive role in decision-making.

Social workers also might find it helpful to explore and map the couples' general decision-making process and what they deem most important in it. They also can explore couples' backgrounds and values that may influence FP decision-making. Further, social workers should be aware of their ethical dilemmas, as they may be more attuned to couples' interactions during case work sessions. As the study suggests that couples do complete each other's narratives and contradict them at times, by paying attention to these, social workers can obtain better insight into the couples' lives and their affect. A discussion about how strongly one feels about having biological children can help couples explore their motivations and reasons for engaging in FP.

This is one of the first studies to explore couples' decision-making in the area of FP; further research needs to be performed to replicate the results and achieve a deeper 
understanding of spouses/partners' responses to infertility and their roles in the decisionmaking process.

\section{Implications for policy}

The ASCO publishes guidelines for providers in the field of oncofertility, and its recommendations cover discussions with patients to facilitate FP decision-making. This research underscores the importance of including spouses in these discussions, and in future updates, these recommendations may suggest to include spouses more when providing support to their patients.

There is ongoing lobbying for federal legislation that requires insurers to cover FP when cancer treatments result in infertility. One may argue that FP care is not lifesaving and that FP techniques are experimental. But according to Cardozo et al., (2017) even though infertility may not be life threatening but fertility preservation is 'life affirming', and FP consultation reduces long term regrets and improve patients' quality of life. This reduces mental health issues evolving in later life of the patients. FP technology has advanced significantly and cryopreservation of embryos, oocytes, and spermatozoa are established techniques ("Ethics Committee of the American Society for Reproductive Medicine", 2013). They are no longer considered experimental. The results from the current study underlines the 'life affirmation' and reduced long term regrets aspects of FP consultation. Hence, it supports legislations in favor of covering these consultations through insurance.

According to the Declaration of Rights of People with Cancer, shared decision making is a fundamental right of cancer patients (Speechley \& Maxine, 2001). FP 
consultation with patients and their spouses is imperative to shared decision making. This study depicts how patients feel about FP decision making with their spouses and supports the patients' rights to shared decision making. Through my study I would argue that the involvement of spouses if patients' want is a right under shared decision making for the patients. Providers not only need to involve patients but also their spouses/partners while doing FP consultations with patients' will.

Overall for policy makers it is imperative to know the will of cancer patients and their needs while getting cancer treatment and its influence on post treatment life. My study explores the importance of FP and FP decision making of the young patients with cancer. This literature is important to support future policies, promoting FP consultations and shared decision making among young couples.

\section{Limitations}

The objective of the study was to understand the roles of spouses/partners in FP decision-making. The findings may support couples who are undergoing similar treatment and have to make such decisions. However, this research has several limitations:

1) The study was conducted by recruiting patients from the same facility using a convenience sample. Hence, there is a sampling limitation. However, it is a diverse sample with multiple ethnicities and other demographic characteristics.

2) Interviews were conducted over the phone to accommodate patients from different cities who came to the facility for treatment. Phone interviews do miss body language and other interactive advantages that one may derive in an in-person interview. 
3) The study did not include same-sex couples and lacked their input.

4) All couples that were studied reported non-distressed relationships. The dynamics of decision-making change if couples are distressed.

5) There are limitations to dyadic interviewing. Couples may provide confirmatory accounts of their share of stories, as these interviews constitute a presentation to the researcher. Thus, they may avoid expressing their differences or challenging each other.

6) As the samples of patients were limited to same-sex, non-distressed couples, the results may not be generalized to same-sex and distressed couples.

Although there were limitations to the study, it may be used to further research on couples' decision-making, particularly studies that explore such areas as spouses/partner's relationships and response to potential loss of fertility that may influence fertility decision-making.

\section{Conclusion}

This qualitative study explored the way couples make FP decisions and the roles spouses/partners play in those decisions. Four major themes, the couples' response to potential fertility loss, spouses/partners' roles, ethical/legal concerns, and recommendations for other couples emerged from the data.

Patients make choices for themselves, but spouses do play significant roles in decision-making. What couples deem important in all manners of topics also influences their FP decisions. Spouses/partners' recommendations to other couples suggested that it 
is important to show concern for the patient/spouse/partner and to attend at least one fertility consultation.

Through the joint interviews, this study also demonstrated that spouses/partners do disagree with patients sometimes during this decision-making and may find their disagreements difficult to express, especially in front of their spouses. This highlights the importance of attending to what spouses/partners may undergo when making FP decisions. They do have emotional needs and play a significant role in FP decisions. Thus, providers should not ignore them while helping patients in the FP decision-making process. Patients alone are not the only stakeholders in this extremely critical decision, and they do depend on their spouses/partners to make it. There is considerable scope for further research in this field, including looking more closely at spouses/partner's values, their response to potential fertility loss, religious preferences, and the couple's relationship and its effect overall.

This area of research is new, and the goal is to provide more support to patients as they make FP decisions by understanding how central the patient's significant other is in the process. 
Tables and Figures

Table 1. Participants' sociodemographic information

\begin{tabular}{|c|c|}
\hline Individual characteristics & $\%(n)$ \\
\hline \multicolumn{2}{|l|}{ Male } \\
\hline White & $83 \%(10)$ \\
\hline Black & $8 \%(1)$ \\
\hline Asian & $0 \%(0)$ \\
\hline Hispanic & $8 \%(1)$ \\
\hline Age, Mean (max, min) & $35(30-45)$ \\
\hline \multicolumn{2}{|l|}{$\underline{\text { Religion }}$} \\
\hline Christian (Catholic) & 0 \\
\hline Christian (Protestant) & $16 \%(2)$ \\
\hline Christian (other) & $58 \%(7)$ \\
\hline Atheist/Agnostic & $8 \%(1)$ \\
\hline Other & $16 \%(2)$ \\
\hline \multicolumn{2}{|l|}{ Education } \\
\hline Some college & $25 \%(3)$ \\
\hline Bachelor's & $41 \%(5)$ \\
\hline
\end{tabular}




\begin{tabular}{|c|c|}
\hline Master's & $16 \%(2)$ \\
\hline Doctoral & $16 \%(2)$ \\
\hline \multicolumn{2}{|l|}{ Female } \\
\hline White & $66 \%(8)$ \\
\hline Black & $8 \%(1)$ \\
\hline Asian & $8 \%(1)$ \\
\hline Hispanic & $16 \%(2)$ \\
\hline Age, Mean (max, min) & $34.9(28-45)$ \\
\hline Age at diagnosis, Mean (max, min) & $32.9 \%(27-43)$ \\
\hline \multicolumn{2}{|l|}{$\underline{\text { Religion }}$} \\
\hline Christian (Catholic) & 0 \\
\hline Christian (Protestant) & $8 \%(1)$ \\
\hline Christian (other) & $25 \%(3)$ \\
\hline Atheist/Agnostic & $42 \%(5)$ \\
\hline Other & $25 \%(3)$ \\
\hline \multicolumn{2}{|l|}{ Education } \\
\hline Some college & $16 \%(2)$ \\
\hline Bachelor's & $58 \%(7)$ \\
\hline
\end{tabular}




\begin{tabular}{|l|l|}
\hline Master's & $8 \%(1)$ \\
\hline Doctoral & $16 \%(2)$ \\
\hline Couples & \\
\hline No. of couples with biological children together & $41 \%(5)$ \\
\hline No. of couples with children from other partners & $8 \%(1)$ \\
\hline No. of couples expecting at time of interview & $8 \%(1)$ \\
\hline No. of couples with no children & $50 \%(6)$ \\
\hline Marital Status & $100 \%(12)$ Non-Distressed \\
\hline Married & $75 \%(9)$ \\
\hline Living together & $25 \%(3)$ \\
\hline Median household income (min, max) & $\$ 150,000(57,000-400,000)$ \\
\hline Distressed/Non-distressed & \\
\hline
\end{tabular}


Figure 1. Ottawa Decision Support Framework
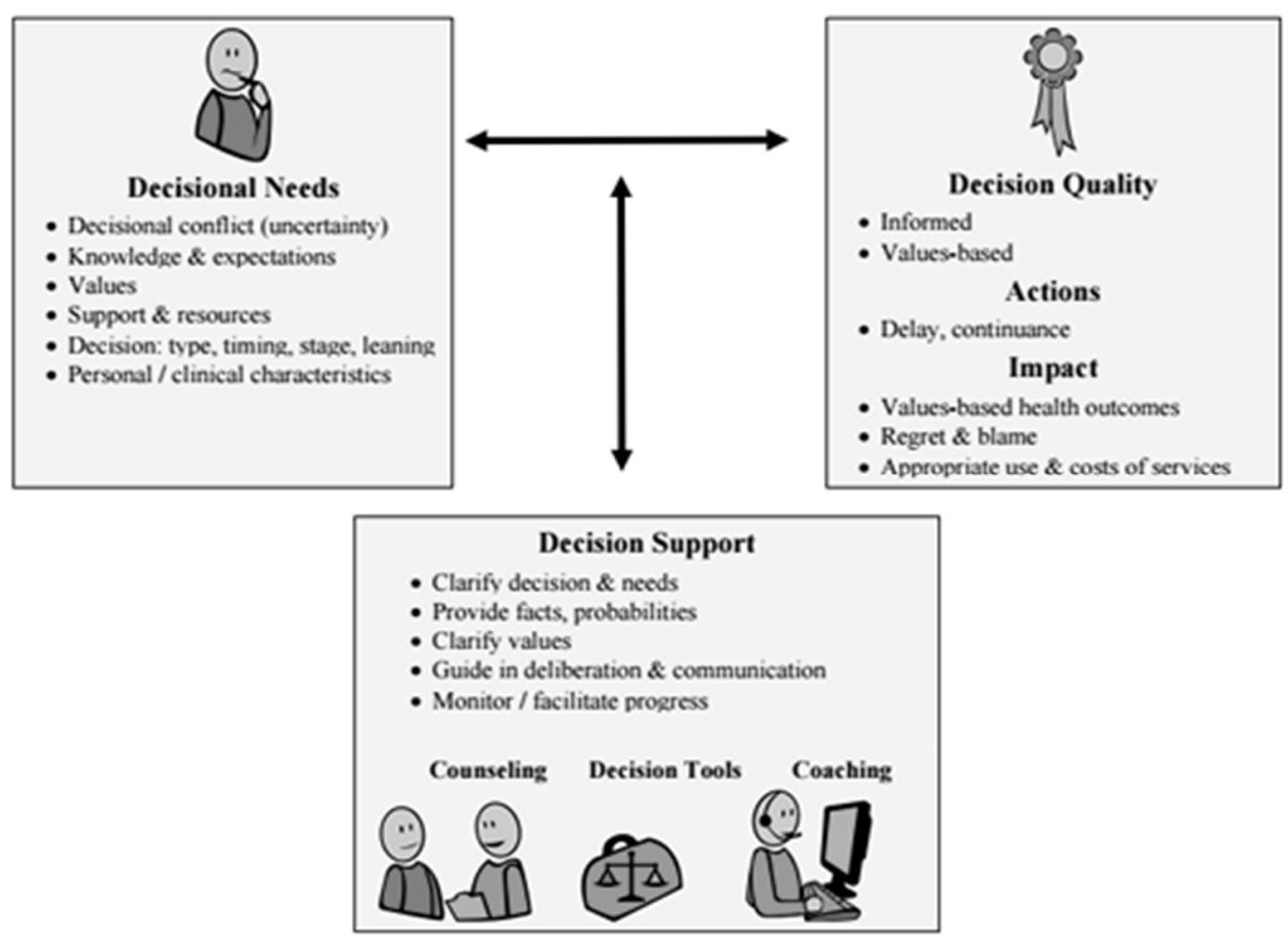
Figure 2. Visual Representation of Themes

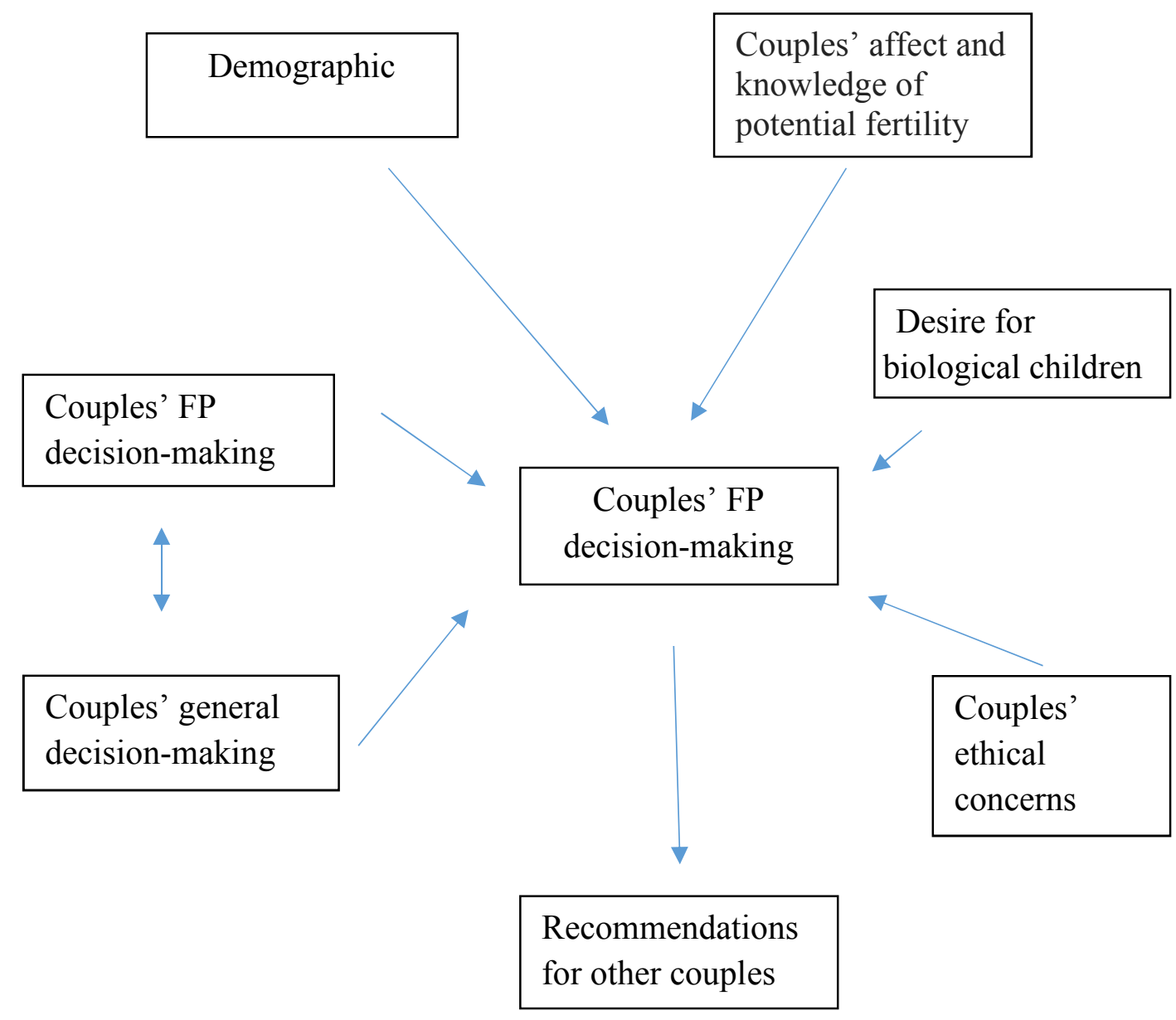


Figure 3. Diagram of themes anchored in Ottawa Decision Support Framework

\begin{tabular}{|l|}
\hline DECISION NEEDS \\
1. Opt for FP \\
2. Couple/Spouse \\
characteristics \\
3. Relationship \\
Status \\
(distressed/non- \\
distressed) \\
4. Decision-making \\
styles \\
5. Desire for \\
biological \\
children
\end{tabular}

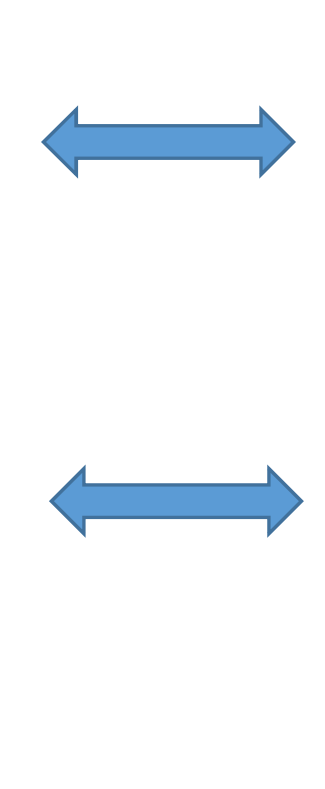

\section{Decision Quality}

1. Ethical considerations

2. Whose decision is it?

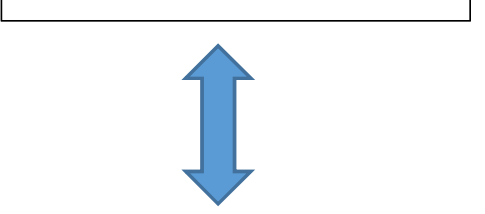

Decision Support

1. Support for Spouses

2. Recommendations 


\section{References}

Ajzen, I., \& Fishbein, M. (1980). Understanding attitudes and predicting social behavior.

Ajzen, I., \& Klobas, J. (2013). Demographic Research Volume 29, Article 8, Pages 203232 Published 31 July 2013.

Ally, M. (2008). Theory and Practice of Online Training: Athabasca University Press.

Al-Homaidan, H. T. (2011). Depression among Women with Primary Infertility attending an Infertility Clinic in Riyadh, Kingdom of Saudi Arabia: Rate, Severity, and Contributing Factors. International Journal of Health Sciences, 5(2), 108-115.

American Cancer Society. Cancer Facts \& Figures 2018. Atlanta: American Cancer Society; 2018.

Anderson, R. A., Weddell, A., Spoudeas, H. A., Douglas, C., Shalet, S. M., Levitt, G., \& Wallace, W. H. B. (2008). Do doctors discuss fertility issues before they treat young patients with cancer? Human reproduction, 23(10), 2246-2251.

AOSW Oncology Social Work Standards of Practice. (2012). Retrieved March 25, 2018, from http://www.aosw.org/professional-development/standards-of-practice/

Arora, N. (2003). Interacting with cancer patients: The significance of physicians' communication behavior. Social Science and Medicine, 57, 791-806.

Ata, B., Chian, R. C., \& Tan, S. L. (2010). Cryopreservation of oocytes and embryos for fertility preservation for female cancer patients. Best practice \& research Clinical obstetrics \& gynaecology, 24(1), 101-112.

Ataman, L. M., Ma, Y., Duncan, F. E., Uzzi, B., \& Woodruff, T. K. (2018). Quantifying the Growth of Oncofertility. Biology of Reproduction. 
Bakker, D., Fitch, M., Gray, R., Reed, E., \& Bennett, J. (2000). Patient-healthcare provider communication during chemotherapy treatment: The perspectives of women with breast cancer. Patient Education and Counselling, 43, 61-71.

Balthazar, U., Deal, A. M., Fritz, M. A., Kondapalli, L. A., \& Kim, J. Y. (2012). The current FP consultation model: Are we adequately informing cancer patients of their options? Human Reproduction, 188.

Bandura, A. (1977). Self-efficacy: Toward a unifying theory of behavioral change. Psychological Review, 84(2), 191.

Barry, Michael J., and Susan Edgman-Levitan. "Shared decision-making—-the pinnacle of patient-centered care." New England Journal of Medicine 366.9 (2012): 780781.

Belch, M. A. (2002). Family decision at the turn of the century: Has the changing structure of households impacted the family decision-making process? Journal of Consumer Behaviour, 2(2), 111.

Bradbury, T. N., \& Fincham, F. D. (1990). Attributions in marriage: Review and critique. Psychological Bulletin, 107(1), 3-33. http://dx.doi.org.proxy.lib.pdx.edu/10.1037/0033-2909.107.1.3

Bredart, Anne, Carole Bouleuc, and Sylvie Dolbeault. "Doctor-patient communication and satisfaction with care in oncology." Current opinion in oncology 17.4 (2005): 351-354.

Brouwers, M., Stacey, D., \& O'Connor, A. (2010). Knowledge creation: synthesis, tools and products. Canadian Medical Association Journal, 182(2), E68-E72. 
Cardozo, E., Huber, W., Stuckey, A., \& Alvero, R. (2017). Mandating Coverage for Fertility Preservation - A Step in the Right Direction. The New England Journal of Medicine,377(17), 1607-1609.

Carpenito-Moyet, L. J. (Ed.). (2006). Nursing diagnosis: Application to clinical practice. Lippincott Williams \& Wilkins.

Carter, J., Rowland, K., Chi, D., Brown, C., Abu-Rustum, N., \& Castiel, M. \&. (2005). Gynecologic cancer treatment and the impact of cancer-related infertility. Gynecologic Oncology, 97(1), 90-95.

Canada, A. L., \& Schover, L. R. (2012). The psychosocial impact of interrupted childbearing in long-term female cancer survivors. Psycho-Oncology, 21(2), 134143.

Charles, Cathy, Amiram Gafni, and Tim Whelan. "Decision-making in the physicianpatient encounter: revisiting the shared treatment decision-making model." Social science \& medicine 49.5 (1999): 651-661.

Charles, C., Gafni, A., \& Whelan, T. (1997). Shared decision-making in the medical encounter: what does it mean? (Or it takes at least two to tango). Social science \& medicine, 44(5), 681-692.

Cedars, M., Letourneau, J., Lisko, M., \& Rosen, M. (Jan 2011). A changing perspective: Improving access to FP. Nature Reviews Clinical Oncology, 8(1), 56.

Clayman, M. L., Harper, M., Quinn, G. P., Shah, S., \& Reinecke, J. (2011). The status of oncofertility resources at NCI-designated comprehensive cancer centers. Journal of Clinical Oncology, 29(15_suppl), 9123-9123. 
Clinical Evidence. How much do we know? [2013]. Available from:

http://clinicalevidence.bmj.com/x/set/static/cms/efficacy-categorisations.html (accessed 9 February 2018).

Coccia, P. F., Pappo, A. S., Beaupin, L., Borges, V. F., Borinstein, S. C., Chugh, R., ... \& Gubin, A. (2018). Adolescent and Young Adult Oncology, Version 2.2018, NCCN Clinical Practice Guidelines in Oncology. Journal of the National Comprehensive Cancer Network, 16(1), 66-97.

Crotty, M. (1998). The foundations of social research. Thousand Oaks, CA; Sage.

Dolmans, M. M. (2011). Children born after auto transplantation of cryopreserved ovarian tissue. A review of 13 live births. Annals of medicine, 43(6), 437-450.

Donnez, J., Jadoul, P., Squifflet, J., Van Langendonckt, A., Donnez, O., Van Eyck, A. S., ... \& Dolmans, M. M. (2010). Ovarian tissue cryopreservation and transplantation in cancer patients. Best practice \& research Clinical obstetrics \& gynaecology, 24(1), 87-100.

Donnez, J., Silber, S., Andersen, C. Y., Demeestere, I., Piver, P., Meirow, D., \&

Duffy CM, Allen SM, Clark MA (2005) Discussions regarding reproductive health for young women with breast cancer undergoing chemotherapy. J Clin Oncol 23 (4): $766-773$

Duncan, F. E., Jozefik, J. K., Kim, A. M., Hirshfeld-Cytron, J., \& Woodruff, T. K. (2011). The gynecologist has a unique role in providing oncofertility care to young cancer patients. US obstetrics \& gynaecology, 6(1), 24.

Editorial. (April 2014). FP and consent. The Lancet Oncology, 15(4), 361. 
Elwyn, Glyn, et al. "Shared decision-making and the concept of equipoise: the competences of involving patients in healthcare choices." Br J Gen Pract50.460 (2000): 892-899.

Eisikovits, Z., \& Koren, C. (2010). Approaches to and outcomes of dyadic interview analysis. Qualitative Health Research, 20(12), 1642-1655.

Elwyn, G., Edwards, A., Hood, K., Robling, M., Atwell, C., Russell, I., \& Grol, R. P. T. M. (2004). Achieving involvement: process outcomes from a cluster randomized trial of shared decision-making skill development and use of risk communication aids in general practice. Family Practice, 21(4), 337-346

Ethics Committee of the American Society for Reproductive Medicine. (2013). Fertility preservation and reproduction in patients facing gonadotoxic therapies: a committee opinion. Fertility and Sterility, 100(5), 1224-1231.

Feather, J. (1980). The book trade in politics: The making of the copyright act of 1710. Publishing history, 8, and 19.

Frosch, Dominick L., and Robert M. Kaplan. "Shared decision-making in clinical medicine: past research and future directions." American journal of preventive medicine 17.4 (1999): 285-294.

Garvelink, M. M., Ter Kuile, M. M., Fischer, M. J., Louwé, L. A., Hilders, C. G., Kroep, J. R., \& Stiggelbout, A. M. (2013). Development of a decision aid about fertility preservation for women with breast cancer in The Netherlands. Journal of Psychosomatic Obstetrics \& Gynecology, 34(4), 170-178. 
Glaser, B., \& Strauss, A. (1967). The discovery of grounded theory Chicago. Adeline, USA.

Glaser, A., Wilkey, O., \& Greenberg, M. (2000). Sperm and ova conservation: existing standards of practice in North America. Pediatric Blood \& Cancer, 35(2), 114118.

Greil, A. L., McQuillan, J., Lowry, M., \& Shreffler, K. M. (2011). Infertility treatment and fertility-specific distress: A longitudinal analysis of a population-based sample of US women. Social Science \& Medicine, 73(1), 87-94.

Gwede, C. K., Vadaparampil, S. T., Hoffe, S., \& Quinn, G. P. (2012). The role of radiation oncologists and discussion of fertility preservation in young cancer patients. Practical radiation oncology, 2(4), 242-247.

Hawkins, M. M., Draper, G. J., \& Smith, R. A. (1989). Cancer among 1,348 offspring of survivors of childhood cancer. International journal of cancer, 43(6), 975-978.

Hoffman, A. S., Volk, R. J., Saarimaki, A., Stirling, C., Li, L. C., Härter, M., et al. (2013). Delivering patient decision aids on the Internet: Definitions, theories, current evidence, and emerging research areas. BMC Medical Informatics and Decision-making, 13(Suppl 2), S13.

International Patient Decision Aids Standards Collaboration. (2013, October 3). IPDAS/What are patient decision aids? Retrieved July 30, 2014, from http://ipdas.ohri.ca/index.html: http://ipdas.ohri.ca/what.html.

James P. Eckman, Christian Ethics, pp. 43-53; Ellen McCarthy, "Fertility Medicine Brings Babies—and Tough Decisions," Washington Post (18 May 2015); Alice 
Park, “The Incredible, Surprising, Controversial New Way to make a Baby, Time (18 May 2015), pp. 42-46.

Janis, I. L., \& Mann, L. (1977). Decision-making: A psychological analysis of conflict, choice, and commitment. New York, NY, US: Free Press.

Jensen, J., Morbeck, D., \& Coddington, C. (2011). FP. Mayo Clinic Proceedings, 86(1).

John, G., Cliff, N., Howard, M., Steve, B., Bruce, Y., \& Mary Ellen, R. (1976). Behavior exchange theory and marital decision-making. Journal of Personality and Social Psychology, 34(1), 14.

Joseph-Williams, N., Newcombe, R., Politi, M., Durand, M. A., Sivell, S., Stacey, D., \& Pignone, M. (2014). Toward minimum standards for certifying patient decision aids: a modified Delphi consensus process. Medical Decision-making, 34(6), 699710.

Keeney, R. L., \& Raiffa, H. (1976). Decision with multiple objectives.

King, L., Quinn, G. P., Vadaparampil, S. T., Miree, C. A., Wilson, C., Clayton, H., \& Zebrack, B. (2008). Oncology social workers' perceptions of barriers to discussing fertility preservation with cancer patients. Social work in health care, 47(4), 479501.

Kumar, A., Merali, A., \& Pond, G. \&. (2012). Fertility risk discussions in young patients diagnosed with colorectal cancer. Current Oncology, 19(3), 155-159. doi:10.3747/co.19.942.

Knobf MT (2001) the menopausal symptom experience in young midlife women with breast cancer. Cancer Nurs 24 (3): 201 - 210; quiz 210-211 
Lee, S. J., Schover, L. R., Partridge, A. H., Patrizio, P., Wallace, W. H., Hagerty, K., ... \& Légaré, F., O'Connor, A. C., Graham, I., Saucier, D., Côté, L., Cauchon, M., \& Paré, L. (2006). Supporting patients facing difficult health care decisions: use of the Ottawa Decision Support Framework. Canadian Family Physician, 52(4), 476-477.

Letourneau, J. M., Ebbel, E. E., Katz, P. P., Katz, A., Ai, W. Z., Chien, A. J., ... \& Rosen, M. P. (2012). Pretreatment fertility counseling and fertility preservation improve quality of life in reproductive age women with cancer. Cancer, 118(6), 17101717.

Levinson, Wendy, Cara S. Lesser, and Ronald M. Epstein. "Developing physician communication skills for patient-centered care." Health Affairs 29.7 (2010): $1310-1318$.

Locke, E. A., \& Latham, G. P. (1990). A Theory of Goal Setting and Task Performance: Prentice-Hall, Inc.

Logan, S., Perz, J., Ussher, J. M., Peate, M., \& Anazodo, A. (2018). A systematic review of patient Oncofertility support needs in reproductive cancer patients aged 14 to 45 years of age. Psycho-Oncology, 27(2), 401-409.

Logan, S., Perz, J., Ussher, J., Peate, M., \& Anazodo, A. (2018). Clinician provision of Oncofertility support in cancer patients of a reproductive age: a systematic review. Psycho-oncology, 27(3), 748-756.

Loren, A. W., Mangu, P. B., Beck, L. N., Brennan, L., Magdalinski, A. J., Partridge, A. H., et al. (2013). FP for patients with cancer: American Society of Clinical 
Oncology Clinical Practice Guideline update. Journal of Clinical Oncology, $31(19), 2500-2510$.

Maltaris, T., Seufert, R., Fischl, F., Schaffrath, M., Pollow, K., Koelbl, H., et al. (2007). The effect of cancer treatment on female fertility and strategies for preserving fertility. European Journal of Obstetrics \& Gynecology and Reproductive, 130(2), $148-155$.

Mayo Clinic Staff. (2014, February 8). http://www.mayoclinic.org/healthy-living/gettingpregnant/in-depth/fertility-preservation. Retrieved July 26, 2014, from http://www.mayoclinic.org/: http://www.mayoclinic.org/healthy-living/gettingpregnant/in-depth/fertility-preservation/art-20047512.

McCaffery, K. J., Holmes-Rovner, M., Smith, S. K., Rovner, D., Nutbeam, D., Clayman, M. L., \& Sheridan, S. L. (2013). Addressing health literacy in patient decision aids. BMC medical informatics and decision-making, 13(2), S10.

Merriam, S. B. (2002). Qualitative research in practice: Examples for discussion and analysis. Jossey-Bass Inc Pub.

Meyer, A., Keszte, J., Wollbrück, D., Dietz, A., Oeken, J., Vogel, H. J., ... \& Schock, J. (2015). Psychological distress and need for psycho-oncological support in spouses of total laryngectomised cancer patients-results for the first 3 years after surgery. Supportive Care in Cancer, 23(5), 1331-1339.

Morgan, D. L., Ataie, J., Carder, P., \& Hoffman, K. (2013). Introducing dyadic interviews as a method for collecting qualitative data. Qualitative health research, 23(9), 1276-1284. 
Noone AM, Howlader N, Krapcho M, Miller D, Brest A, Yu M, Ruhl J, Tatalovich Z, Mariotto A, Lewis DR, Chen HS, Feuer EJ, Cronin KA (eds). SEER Cancer Statistics Review, 1975-2015, National Cancer Institute. Bethesda, MD, https://seer.cancer.gov/csr/1975 2015/, based on November 2017 SEER data submission, posted to the SEER web site, April 2018. International Patient Decision Aid Standards Collaboration. Background Document [2005]. Available from: http://ipdas.ohri.ca/IPDAS_Background.pdf (accessed 9 Feb 2018).

Norbeck, J. S. (1988). Social support. Annual review of nursing research, 6, 85. Noyes, N., Boldt, J., \& Nagy, Z. P. (2010). Oocyte cryopreservation: is it time to remove its experimental label? Journal of assisted reproduction and genetics, $27(2-3), 69-74$.

O'Brien, M. A., Whelan, T. J., Villasis-Keever, M., Gafni, A., Charles, C., Roberts, R., ... \& Cai, W. (2009). Are cancer-related decision aids effective? A systematic review and meta-analysis. Journal of Clinical Oncology, 27(6), 974-985.

O’Connor, A. M., Stacey, D., \& Jacobsen, M. J. (2011). Ottawa Decision Support Tutorial (ODST). Improving practitioners' decision support skills. Ottawa Hospital Research Institute: Patient Decision Aids.

Oktay, K. (2006). American Society of Clinical Oncology recommendations on fertility preservation in cancer patients. Journal of clinical oncology, 24(18), 2917-2931.

Oktay K, Buyuk E, Libertella N, Akar M, Rosenwaks Z (2005) Fertility preservation in breast cancer patients: a prospective controlled comparison of ovarian stimulation 
with tamoxifen and letrozole for embryo cryopreservation. J Clin Oncol 23 (19):

4347 - 4353 Oncofertility Consortium. (2013).

http://oncofertility.northwestern.edu/partner-and-spouse-involvement-fertility-

preservation. Retrieved July 7, 2014, from Oncofertility.northwestern.edu:

http://oncofertility.northwestern.edu/partner-and-spouse-involvement-fertilitypreservation.

Orem, D. E., Taylor, S. G., \& Renpenning, K. M. (1995). Nursing concepts of practice. Panagiotopoulou, N., Ghuman, Sandher, Herbert, \& Stewart. (2018). Barriers and facilitators towards fertility preservation care for cancer patients: A metasynthesis. European Journal of Cancer Care. 27(1), E12428.

Partridge AH, Gelber S , Peppercorn J , Sampson E , Knudsen K, Laufer M , Rosenberg R, Przypyszny M, Rein A, Winer EP ( 2004 ) Web-based survey of fertility issues in young women with breast cancer . J Clin Oncol 22 (20): $4174-4183$

Partridge A, Gelber S, Gelber RD, Castiglione-Gertsch M, Goldhirsch A, Winer E (2007) Age of menopause among women who remain premenopausal following treatment for early breast cancer: long-term results from International Breast Cancer Study Group Trials V and VI. Eur J Cancer 43 (11): 1646 - 1653

Peate, M., Meiser, Cheah, Saunders, Butow, Thewes, Friedlander. (2012). making hard choices easier: A prospective, multicenter study to assess the efficacy of a fertility-related decision aid in young women with early-stage breast cancer. British Journal of Cancer. 106(6), 1053-1061. 
Peddie, V. L., Porter, M. A., Barbour, R., Culligan, D., MacDonald, G., \& King, D. (2012). Factors affecting decision-making about FP after cancer diagnosis: A qualitative study. Ann International Journal of Obstetrics \& Gynecology, 119(9), 1049-1057.

Petty, R. E., \& Cacioppo, J. T. (1986). The elaboration likelihood model of persuasion. Advances in Experimental Social Psychology, 19, 123-205.

Petty, R. E., Heesacker, M., \& Hughes, J. N. (1997). The elaboration likelihood model: Implications for the practice of Social Psychology. Journal of Social Psychology, 35(2), 107-136.

Polak, L., \& Green, J. (2016). Using joint interviews to add analytic value. Qualitative health research, 26(12), 1638-1648.

Quinn, G.P., Vadaparampil, S.T., Gwede, C.K. et al. J Cancer Surviv (2007) 1: 146. Doi: 10.1007/s11764-007-0019-9.

Quinn, G. P., Vadaparampil, S. T., Lee, J. H., Jacobsen, P. B., Bepler, G., Lancaster, J., ... \& Albrecht, T. L. (2009). Physician referral for fertility preservation in oncology patients: a national study of practice behaviors. Journal of clinical oncology, 27(35), 5952-5957.

Quinn GP, Vadaparampil ST, Bell-Ellison BA, Gwede CK, Albrecht TL (2008) Patientphysician communication barriers regarding fertility preservation among newly diagnosed cancer patients. Soc Sci Med 66 (3): 784 - 789 
Radcliffe, E., Lowton, K., \& Morgan, M. (2013). Co-construction of chronic illness narratives by older stroke survivors and their spouses. Sociology of health \& illness, 35(7), 993-1007.

Raven, B. H., Centers, R., \& Rodrigues, A. (1975). The bases of conjugal power. Power in families, 217-232.

Rosenstock, I. M., Strecher, V. J., \& Becker, M. H. (1988). Social learning theory and the health belief model. Health Education \& Behavior, 15(2), 175-183.

Schover, L. R., Brey, K., Lichtin, A., \& Lipshultz, L. I. (2002). Oncologists' attitudes and practices regarding banking sperm before cancer treatment. Journal of Clinical Oncology, 20(7), 1890-1897.

Schover, L. R., Rybicki, L. A., Martin, B. A., \& Bringelsen, K. A. (1999). Having children after cancer. Cancer, 86(4), 697-709.

Schwartz, L. A., Mao, J. J., DeRosa, B. W., Ginsberg, J. P., Hobbie, W. L., Carlson, C. A., ... \& Kazak, A. E. (2010). Self-reported health problems of young adults in clinical settings: survivors of childhood cancer and healthy controls. The Journal of the American Board of Family Medicine, 23(3), 306-314.

Sender, L. S. (2011). A new journal to improve care for adolescent and young adult oncology patients and survivors.

Sheth, K. R., Sharma, V., Helfand, B. T., Cashy, J., Smith, K., Hedges, J. C., ... \& Brannigan, R. E. (2012). Improved fertility preservation care for male patients with cancer after establishment of formalized oncofertility program. The Journal of urology, 187(3), 979-986. 
Shimizu, C., Bando, H., Kato, T., Mizota, Y., \& Yamamoto, S. (2012). Physicians’ knowledge, attitude, and behavior regarding fertility. The Japanese Breast Cancer Society.

Speechley, V., \& Rosenfield, M. (2001). Cancer - the 'at your fingertips' guide: the 'at your fingertips' guide: the comprehensive cancer reference book for the 21 st century. Retrieved from https://ebookcentral-proquest-com.proxy.lib.pdx.edu

The Johns Hopkins University. (2014). Breast cancer survivorship care. Retrieved 0527 , 2014, from www.hopkinsmedicine.org: http://www.hopkinsmedicine.org/avon_foundation_breast_center/treatments_servi ces/survivor_care/fertility_after_cancer.html.

Stacey, D., Bennett, C. L., Barry, M. J., Col, N. F., Eden, K. B., Holmes-Rovner, M., \& Thomson, R. (2011). Decision aids for people facing health treatment or screening decisions. Cochrane Database Syst Rev, 10(10).

Swasy, John L. (1979),"Measuring the Bases of Social Power", in NA - Advances in Consumer Research Volume 06, eds. William L. Wilkie, Ann Abor, and MI: Association for Consumer Research, Pages: 340-346.

Thewes B, Butow P, Girgis A, Pendlebury S (2004). The psychological needs of breast cancer survivors; a qualitative study of the shared and unique needs of younger vs older survivors. Psycho-Oncology $13: 177-189$

Thewes B , Meiser B , Taylor A, Phillips KA, Pendlebury S , Capp A, Dalley D, Goldstein D , Baber R, Friedlander ML ( 2005 ) Fertility- and menopause-related 
information needs of younger women with a diagnosis of early breast cancer . $J$ Clin Oncol 23 (22): 5155 - 5165

Thewes B, Meiser B, Rickard J, Friedlander M (2003).The fertility- and menopauserelated information needs of younger women with a diagnosis of breast cancer: a qualitative study. Psycho-Oncology 12 (5): 500 - 511

Tschudin, S., Bunting, L., Abraham, J., Gallop-Evans, E., \& Fiander, A \&. (2010). Correlates of fertility issues in an Internet survey of cancer survivors. Journal of Psychosomatic Obstetrics \& Gynecology, 31(3), 150-157.

Tversky, A., \& Kahneman, D. (1981). The framing of decisions and the psychology of choice. Science, 211(4481), 453-458.

Vadaparampil, S. T., Christie, J., Quinn, G. P., Fleming, P., Stowe, C., \& Bower, B. A. (October, 2012). A pilot study to examine patient awareness and provider discussion of the impact of cancer treatment fertility in a registry-based sample of African American Women with breast cancer. Supportive Care in Cancer, 20(10), 2559-2564. Doi: 10.1007/s00520-012-1380-4.

Wright, J., Duchesne, C., Sabourin, S., Bissonnette, F., Benoit, J., \& Girard, Y. (1991). Psychosocial distress and infertility: men and women respond differently. Fertility and sterility, 55(1), 100-108.

Verhaak, C. M., Smeenk, J. M., Evers, A. W., Kremer, J. A., \& Kraaimaat, F. W. (2007). What Are Social Workers' Roles in Oncofertility? (2015). Retrieved March 25, 2018, from http://oncofertility.northwestern.edu/resources/social-workers\#SWrole 
Women's emotional adjustment to IVF: A systematic review of 25 years of research. . Human Reproduction Update, 13(1), 27-36.

Waimey, K. E., Duncan, F. E., Su, H. I., Smith, K., Wallach, H., Jona, K., \& Chang, R. J. (2013). Future directions in oncofertility and fertility preservation: a report from the 2011 oncofertility consortium conference. Journal of adolescent and young adult oncology, 2(1), 25-30.

Warin, J., Solomon, Y., \& Lewis, C. (2007). Swapping stories: Comparing plots: Triangulating individual narratives within families. International Journal of Social Research Methodology, 10(2), 121-134.

Weston, W. W. (2001). Informed and shared decision-making: the crux of patientcentered care. Canadian Medical Association Journal, 165(4), 438-439.

Woodard, T. L., Hoffman, A. S., Covarrubias, L. A., Holman, D., Schover, L., Bradford, A., \& Volk, R. J. (2017). The Pathways fertility preservation decision aid website for women with cancer: development and field testing. Journal of Cancer Survivorship, 1-14.

Woodard, T. L., Hoffman, A. S., Covarrubias, L. A., Holman, D., Schover, L., Bradford, A., \& Volk, R. J. (2017). The Pathways fertility preservation decision aid website for women with cancer: development and field testing. Journal of Cancer Survivorship, 1-14.

Woodruff, T. K. (2010). The Oncofertility Consortium—addressing fertility in young people with cancer. Nature reviews Clinical oncology, 7(8), and 466. 
Woodruff, D. T. (2007). The emergence of a new interdisciplinary: Oncofertility. In D. T. Woodruff (Ed.), Oncofertility FP for Cancer Survivors. Chicago, IL: Springer US, pp. 3-11.

Woodruff, T. K., Clayman, M. L., \& Waimey, K. E. (2014). Oncofertility

Communication: Sharing Information and Building Relationships across

Disciplines. New York, NY: Springer. 


\section{Appendix A}

Demographic Questionnaire

Study ID \#:

Date/Time\#:

Please complete these questions by marking an X next to the answer that best describes you or by filling in the blank. These questions are for research purposes only and your answers will be kept strictly confidential.

1. How old are you currently? Years

2. How old were you when you were diagnosed with cancer? Years

3. What is your race? Please check all that apply.

American Indian or Alaska Native

Asian

Black or African American

Native Hawaiian or Other Pacific Islander

White 
Other:

4. What is your ethnicity?

Hispanic or Latino

Not Hispanic or Latino

5. What is your household income per year (in US dollars)?

$\$$ per year

6. What religion do you most closely identify with?

Atheism/Agnosticism
Buddhism
Christianity (Protestant)
Christianity (Catholic)
Christianity (Other)
Hinduism
Islam
Judaism
Other

Please identify: 
7. What is the highest grade/level of education that you have completed? Less than high school High school (grades 9-12, no degree)

High school graduate (or equivalent)

Some college (no degree) Associate's degree (including occupational or academic degrees)

Bachelor's degree (BA, BS, AB, etc.)

Master's degree (MA, MS, MSW, etc.)

Professional school degree (MD, DDC, JD, etc.)

Doctoral degree $(\mathrm{PhD}, \mathrm{EdD}$, etc.)

8. Please check the relationship category that best describes your situation currently.

Single

In a relationship

Married

Divorced

Widowed

Other-Please describe:

9. Please check the category that best describes your living arrangements currently. 
Alone

With spouse

With opposite sex partner (unmarried)

With same sex partner (unmarried)

With others (e.g., friends, family)

10. Please check the relationship category that would best describe your situation when you were diagnosed with cancer.

Single

In a relationship

Married

Divorced

Widowed

Other

Please describe:

11. Please check the category that best describes your living arrangements when you were diagnosed with cancer.

Alone

With spouse 
With opposite sex partner (unmarried)

With same sex partner (unmarried)

With others (e.g., friends, family)

Approximately when did you learn about cancer diagnosis-?

Have you been for first fertility consultation: No Yes?

If yes then approximately when:

Number of biological children with the current spouse:

Number of biological children from previous marriage (if any):

Number of children who stay with you in the household

How is your relationship with your spouse? Is it distressed or not distressed from before cancer diagnosis

How would you describe the relationship now? Distresses and not distressed

How many children do you think you want to have?

Are you planning to have children in future? 


\section{Appendix B}

\section{INTERVIEW GUIDE}

I would like to invite both of you an hour and half interview. I would like to learn more about how you and your spouse are trying to reach to FP decision. I want to know about your experiences, conversations and discussions on fertility preservation and how is this impacting your relationship?

I will ask you both some questions together and then will interview the partner individually without the presence of the patient.

\section{CONJOINT INTERVIEW}

1) What is most important to you in making decisions in your relationship...?

(Examples: mutual

Satisfaction, equity, fairness, shared communication, etc.).

- What does mean to each of you?

- How do you define in your relationship?

- Help me to understand in your decision-making

· What does __ look like?

- How do you make decisions in this way?

2) How does this apply to your current problem of FP decision-making?

- Is it different from other decisions? 
- What makes it different?

3) How do you work it out when you disagree on a decision?

What does that process look like?

- What happens next?

4) What were the disagreements in FP decision-making?

- How did differ in your opinion?

4) How did you work out your disagreements in FP decision-making?

Prompts; is it different to work it out this time than you usually do for other major decisions

5) Tell me about a time when you made a decision where both of you were satisfied.

6) How and when you both reached an agreement and were satisfied about FP decision?

7) Tell me about a time when both of you together made a medical decision together apart from FP?

Prompts: Can be about having kids? Any surgery? Or any other major decision linked to the health of either partner.

8) How is the situation similar or different in FP decision-making than any other medical decision in the past?

Prompts: Involvement, unpredictability, lack of information.

9) What are strengths and weaknesses of your relations that helped or hindered FP decisions?

INDIVIDUAL INTERVIEW (SPOUSE/PARTNER OF PATIENT) YOU'RE STORY 
1. Can you describe what happens when you first came to know about fertility compromise of your spouse?

Prompts: Who talked to you? When was this discussed? Were there other family members when you first came to know?

2. How important is it to you that your partner be able to have her own biological child in the future?

Prompts: Family lineage, attachment to the child, family acceptance.

3. How important is it to you that you be able to have your own biological child in the future?

Prompts: Would you be comfortable with a child conceived from your sperm but an egg from a donor? Would you be comfortable adopting a child?

\section{DEFINING FERTILITY PRESERVATION AND INFORMATION}

4. Tell me in your own words what fertility preservation is.

5. Before your spouse began [cancer] treatment, did you know that there is an option of pursuing fertility preservation?

Prompts;

- How did you first hear that you both could pursue fertility preservation?

- When you learned that your partner/spouse could pursue fertility preservation, what were your first thoughts?

6. What do you think will happen to your partner after cancer treatment? Prompts: Emotional issues, physical issues 
7. What do you think is likely to happen to your partner's fertility after her cancer treatment?

Prompts: Were you included in discussions with the doctors about fertility? Do you feel comfortable with the amount of information you have?

8. What do you think are the main advantages of your partner going through fertility preservation? Or not going through fertility preservation.

Prompts: How can the family benefit from FP? Does it bring hope, confidence to the family?

9. What will happen if you moved forward with it? Or if you do not do this.

10. Do you have some worries or concerns about your partner going through fertility preservation?

Prompts: Do you worry it could delay her cancer treatment too much? Are you worried about the cost?

\section{SUPPORT IN DECISION-MAKING}

11. What do you think should be your role in the decision about fertility preservation?

Prompts: Should it be her choice alone? Should you have some say in her choice? Should each partner have an equal say?

12. What do you think your partner wants to do about fertility preservation?

Prompts: how do you think she wants to proceed with it?

13. Who will make this final decision?

Prompts: Is it going to be just you two or other family members will be involved?

14. Do you have any religious or legal concerns about fertility preservation? 
15. Lastly I would like to ask if you received the support from the providers to make this decision.

16. How do you think Oncofertility consultation can involve spouses more?

a. Prompts- support that spouses need to reach a decision

\section{CLOSING}

"If there is anything we have not discussed and you feel it would be important to add to the study, please feel free to share at this time... thank you for your participation.” 


\section{Appendix C}

\section{Consent Form}

\section{INFORMED CONSENT/AUTHORIZATION FOR PARTICIPATION IN}

RESEARCH WITH OPTIONAL PROCEDURES

Study- Role of spouse/partner in fertility preservation decision-making by young women with cancer.

Researcher- Aakrati Mathur

Study chair- Dr. Terri L. Woodard

Participant's name:

\section{Check relation to the patient with Cancer: Self or Spouse/domestic partner}

Medical Record number/Study Id

Email address

Phone Number

You are being asked to take part in this psychosocial research study at The University of Texas MD Anderson Cancer Center ("MD Anderson"). This consent and authorization form explains why this research study is being done and what your role will be if you choose to take part. This form also describes the possible risks connected with being in this study. After reviewing this information with the person responsible for your enrollment, you should know enough to be able to make an informed decision on whether you want to take part in the study. 
You are being asked to take part in this study because you are the woman or

spouse/domestic partner of a woman between the ages of 18 and 45 who has been diagnosed with cancer.

\section{1) Purpose of the Study}

The goal of this research study is to collect information about factors that influence decisions about fertility preservation from women between the ages of 18 and 45, who have been diagnosed with cancer and their spouses. The main objective is to understand the role of partner in fertility preservation decision-making by focusing on their preferences on fertility preservation methods, whether they are aware of the various methods and how their future family goals compare with that of their women counterparts. Fertility preservation involves taking drugs to stop or control ovary function in order to freeze eggs and/or embryos. Freezing eggs and/or embryos may increase the chances of having a biologic child in the future.

The information collected from this study will be used to create a booklet and web-based informational aid that may help future patients make decisions about fertility preservation.

\section{DESCRIPTION OF STUDY}

If you agree to take part in this study, you will have a telephonic interview with a member of the study. There will be one 45 minute interview conjoint with your spouse and one 45 minute individual interview without the presence of the spouse. Before you take part in an interview you will complete 1 questionnaire about your age, sex, education level and other demographic information. These should take about 10 minutes to 
complete. This questionnaire will be emailed to you. You will provide your phone number in the email and times when you are available for interview. In the interview you will be asked up to 20 questions about your relationship and what factors influenced your decision-making process about fertility preservation, such as personal attitudes, belief systems, and financial considerations. The interview should take about 1 hour.

\section{This is an investigational study and will be of no cost to you.}

\section{RISKS, SIDE EFFECTS, AND DISCOMFORTS TO PARTICIPANTS}

You should discuss the risks of interviews and questionnaires with the study chair. The known risks are listed in this form, but they will vary from person to person. Some questions may make you feel upset or uncomfortable. You may refuse to answer any question. If you have concerns about completing the questionnaires or participating in interview, you are encouraged to contact your doctor or the study chair. Although every effort will be made to keep study data safe, there is a chance that your personal health information could be lost or stolen. All study data will be stored in password-protected computers and/or locked file cabinets. There will be no personal identifying information connected to your questionnaire and interview. The study data will be destroyed right after the study has been published.

This study may involve unpredictable risks to the participants.

\section{POTENTIAL BENEFITS}

Future patients may benefit from what is learned. There are no benefits for you in this study.

\section{ALTERNATIVE PROCEDURES OR TREATMENTS}


You may choose not to take part in this study.

\section{OPTIONAL PROCEDURES FOR THE STUDY}

If you agree, the research staff may contact you by phone or mail to ask if you would be interested in taking part in future research studies. There are no benefits to you for taking part in the optional procedure. You may stop taking part at any time. There will be no cost to you for taking part in the optional procedure. You do not have to agree to take part in the optional procedures in order to be enrolled in this study.

\section{Optional Procedure Risks:}

If you are contacted about future studies, other people may learn that one family member (Had) cancer. This may be upsetting.

Circle your choice of "yes" or "no" for each of the following optional procedures:

Do you agree to allow the research staff to contact you to ask if you would be? Interested in taking part in future research studies?

YES

NO

\section{Additional Information}

7. You may ask the study chair any questions you have about this study. You may contact the study chair, Dr. Terri L. Woodard, at 713-745-7591. You may also contact the Chair of MD Anderson's Institutional Review Board (IRB - a committee that reviews research studies) at 713-792-2933 with any questions that have to do with this study or your rights as a study participant. 
8. Your participation in this research study is strictly voluntary. You may choose not to take part in this study without any penalty or loss of benefits to which you are otherwise entitled. You may also withdraw from participation in this study at any time without any penalty or loss of benefits. If you withdraw from this study, you can still choose to be treated at MD Anderson.

9. This study or your participation in it may be changed or stopped at any time by the study chair, The University of Texas MD Anderson Cancer Center Duncan Family Institute, or the IRB of MD Anderson.

10. You will be informed of any new findings that might affect your willingness to continue taking part in the study.

11. MD Anderson may benefit from your participation and/or what is learned in this study.

12. This study is supported by: The University of Texas MD Anderson Cancer Center Duncan Family Institute

\section{STUDY COSTS AND COMPENSATION}

If you suffer injury as a direct result of taking part in this study, MD Anderson health providers will provide medical care. However, this medical care will be billed to your insurance provider or you in the ordinary manner. You will not be reimbursed for expenses or compensated financially by MD Anderson or The University of Texas MD Anderson Cancer Center Duncan Family Institute for this injury. You may also contact the Chair of MD Anderson's IRB at 713-792-2933 with questions about study-related injuries. By signing this consent form, you are not giving up any of your legal rights. 
Unless otherwise stated in this consent form, all of the costs linked with this study, which are not covered by other payers (health maintenance organization [HMO], health insurance company, etc.), will be your responsibility. There are no plans to compensate you for any patents or discoveries that may result from your participation in this research. If you are the spouse/domestic partner of the woman with cancer you may be given a $\$ 10$ gift card for your time and effort in completing the interview.

\section{Authorization for Use and Disclosure of Protected Health Information:}

A. During the course of this study, the research team at MD Anderson will be collecting Information about you that they may share with the parties named in Section D below. B. Signing this consent and authorization form is optional. However, if you refuse to provide authorization to use and disclose your protected health information for this study, you will not be able to participate in this research study.

C. MD Anderson will take appropriate steps to keep your protected health information private when possible, and it will be protected according to state and federal law.

However, there is no guarantee that your information will remain confidential, and it may be re-disclosed at some point. Federal agencies (such as the Office for Human Research Protections [OHRP - a regulatory agency that oversees research in humans]), The University of Texas MD Anderson Cancer Center Duncan Family Institute, and the IRB of MD Anderson might view or receive your record in order to collect data and/or meet legal, ethical, research, and safety-related obligations. In some situations, health authorities could be required to reveal the names of participants.

D. Your study information may be shared with the following parties: 
- The University of Texas MD Anderson Cancer Center Duncan Family Institute

- (and/or any future sponsors of the study)

- The OHRP

- The IRB of MD Anderson

- Officials of MD Anderson

- Study monitors who verify the accuracy of the information including Portland State University faculty member involved in the research

- Individuals who put all the study information together in report form

E. Normally you have a right to access your study information. However, in order to preserve the integrity of this research study, you will not be permitted to have access to certain portions of your study information while the study is ongoing.

F. There is no expiration date for the use of your information as stated in this authorization. You may withdraw your authorization to share your protected health information at any time in writing. Instructions on how to do this can be found in the MD Anderson Notice of Privacy Practices (NPP). You may contact the IRB Staff at 713-7922933 with questions about how to find the NPP. If you withdraw your authorization, you will be removed from the study and the study chair and staff will no longer use or disclose your protected health information in connection with this study, unless the study chair or staff needs to use or disclose some of your research-related protected health information to preserve the scientific value of the study. Data collected about you up to the time you withdrew will be used and included in the data analysis. The parties listed in 
Section D above may use and disclose any study data that were collected before you canceled your authorization.

\section{CONSENT/AUTHORIZATION}

I understand the information in this consent form. I have had a chance to read the consent form for this study, or have had it read to me. I have had a chance to think about it, ask questions, and talk about it with others as needed. I give the study chair permission to enroll me on this study. By signing this consent form, I am not giving up any of my legal rights. I will be given a signed copy of this consent document.

Signature of Participant

Date

\section{PERSON OBTAINING CONSENT}

I have discussed this psychosocial research study with the participant and/or his or her authorized representative, using language that is understandable and appropriate. I believe that I have fully informed this participant of the nature of this study and its possible benefits and risks and that the participant understood this explanation.

SIGNATURE OF STUDY CHAIR

OR PERSON AUTHORIZED 


\section{Appendix D \\ IRB Approval}

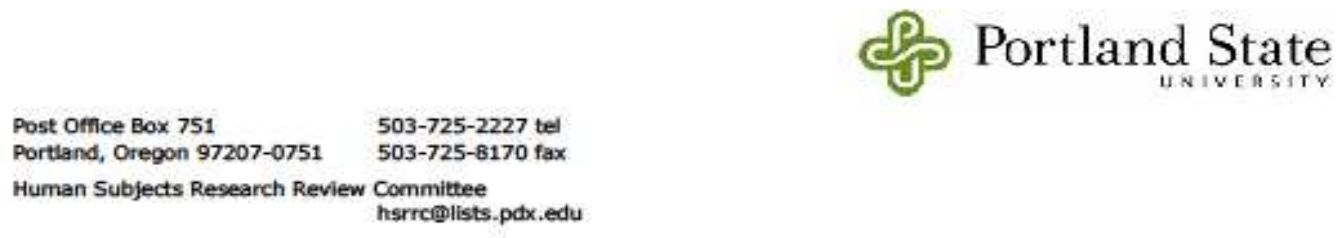

Date: July 27,2015

To: Roberto Orellana / Aakrati Mathur

From Karen Cellarius, HSRRC Chair

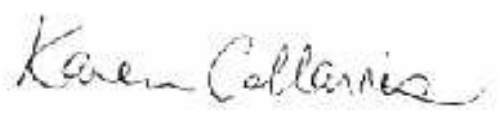

Re: HSRRC approval for your project tifled, "Role of Spouse/Partner in FP Decision Malking by Young Women with Cancer" HSRRC Proposal \# 153513

Approval-Expiration: July 27, 2015 - July 26, 2016

Review Type: Expedited, Categonies 6,7

In accordance with your request, the PSU Human Subjects Research Review Committee has reviewed your request for approval of the project referenced above for conmpliance with PSU and DHHS policies and regulations covering the protection of human subjects. The Committee is satisfied that your provisions for protecting the rights and welfare of all subjects participating in the research are adequate, and your project is approved Please note the following requirements:

Approval: You are approved to conduct this research study only during the peniod of approval cited above; and the research must be conducted according to the plans and protocol submitted (approved copy enclosed).

Consent: Consent is waived from all participants in this study, as this project is analysis of data collected from a study approved by Vurginia Tech

Changes to Protocol: Any changes in the proposed study, whether to procechures, survey instruments, consent forms or cover letters, must be outlined and submitted to the Committee immediately. The proposed changes cannot be implemented before they have been reviewed and approved by the Committee.

Continuing Reriew: This appronal will expire on 07/26/2016. It is the investigator's responsibility to ensure that a Continuing Review Report on the status of the project is submitted to the HSRRC two months before the expiration date, and that approval of the study is kept current. The IRB offices does not send out notifications of expiration dates. The Continumg Review Report is available at www.rsp.pdxedu/compliance_human.php and in the Office of Research and Strategic Partnerships (RSP).

Adverse Reactions and/or Unanticipated Problems: If any adverse reactions or unanticipated problems oceur as a result of this study, you are required to notify the Committee immediately. If the issue is serious, approval may be withdrawn pending an investigation by the Committee.

Completion of Study: Please notify the Committee as soon as your research has been conmpleted. Study records, including protocols and signed consent forms for each participant, must be kept by the investigator in a secure location for three years following completion of the study (or per any requirements specified by the project's funding agency).

If you have questions or concerns, please contact the Office of Research Integrity in the PSU RSP at 503-725-2227. 